\title{
Age-Related Intraneuronal Aggregation of Amyloid- $\beta$ in Endosomes, Mitochondria, Autophagosomes, and Lysosomes
}

\author{
Gregory J. Brewer ${ }^{\mathrm{a}, \mathrm{b}, *}$, Robert A. Herrera ${ }^{\mathrm{b}}$, Stephan Philipp ${ }^{\mathrm{c}}$, Justyna Sosna ${ }^{\mathrm{c}}$, \\ Jorge Mauricio Reyes-Ruiz ${ }^{\mathrm{c}}$ and Charles G. Glabe ${ }^{\mathrm{a}, \mathrm{c}}$ \\ ${ }^{a}$ MIND Institute, Center for Neurobiology of Learning and Memory, Irvine, CA, USA \\ ${ }^{\mathrm{b}}$ Department of Biomedical Engineering, University of California Irvine, Irvine, CA, USA \\ ${ }^{\mathrm{c}}$ Department of Molecular Biology, University of California Irvine, Irvine, CA, USA
}

Accepted 17 October 2019

\begin{abstract}
This work provides new insight into the age-related basis of Alzheimer's disease (AD), the composition of intraneuronal amyloid (iA $\beta$ ), and the mechanism of an age-related increase in $\mathrm{iA} \beta$ in adult AD-model mouse neurons. $\mathrm{A}$ new end-specific antibody for $A \beta_{45}$ and another for aggregated forms of $A \beta$ provide new insight into the composition of iA $\beta$ and the mechanism of accumulation in old adult neurons from the $3 \mathrm{xTg}-\mathrm{AD}$ model mouse. iA $\beta$ levels containing aggregates of $A \beta_{45}$ increased 30-50-fold in neurons from young to old age and were further stimulated upon glutamate treatment. iA $\beta$ was 8 times more abundant in 3xTg-AD than non-transgenic neurons with imaged particle sizes following the same $\log$-log distribution, suggesting a similar snow-ball mechanism of intracellular biogenesis. Pathologically misfolded and mislocalized Alz50 tau colocalized with iA $\beta$ and rapidly increased following a brief metabolic stress with glutamate. A $\beta P P-$ CTF, $A \beta_{45}$, and aggregated $A \beta$ colocalized most strongly with mitochondria and endosomes and less with lysosomes and autophagosomes. Differences in iA $\beta$ by sex were minor. These results suggest that incomplete carboxyl-terminal trimming of long A $\beta$ s by gamma-secretase produced large intracellular deposits which limited completion of autophagy in aged neurons. Understanding the mechanism of age-related changes in iA $\beta$ processing may lead to application of countermeasures to prolong dementia-free health span.
\end{abstract}

Keywords: Aging, Alzheimer's disease, amyloid, autophagosomes, endosomes, lysosomes, mitochondria

\section{INTRODUCTION}

Age has long been known to be the most significant risk factor for $\mathrm{AD}$, but how age is related to disease and whether the relationship is mediated through amyloid- $\beta(A \beta)$ and tau pathology remains unknown. The amyloid hypothesis [1-3] has formed the basis for the development and testing of many therapeutics; however, none of these have been successful and the gamma-secretase inhibitor, Semagacestat, actually led to a significant worsening of functional ability in

\footnotetext{
${ }^{*}$ Correspondence to: Greg Brewer, Department of Biomedical Engineering, University of California Irvine, Irvine, CA 92697, USA. E-mail: GJBrewer@uci.edu.
}

human clinical trials [4]. Although gamma-secretase inhibitors were screened on the basis of their inhibition of the secretion of $A \beta$, a detailed analysis of the mechanism indicated that Semagacestat slows the tripeptide carboxypeptidase terminal triming of the primary products of gamma-secretase endoproteolysis leading to the accumulation of "long A $\beta \mathrm{s}$ " ending at residues $45,46,48$, and 49 of the $A \beta$ sequence (Fig. 1), similar to many of the FAD mutations in presenilin, which interfere with the processivity of the tripeptidase trimming [5-7]. These results suggest that the reason that Semagacestat and Avagacestat [8] caused cognitive worsening is the same reason that FAD mutations in presenilins cause early onset 


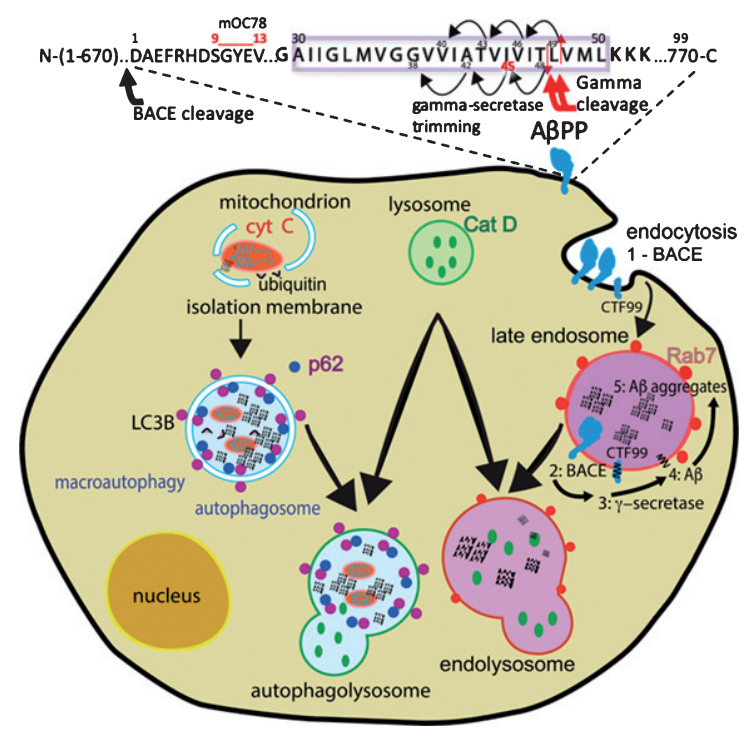

Fig. 1. Routes for intracellular $A \beta$ for aggregation of insoluble "long A $\beta$ " peptides. Above, red arrows mark initial endoprotease cleavage of $A \beta P P$. Smaller black arrows show trimming to $A \beta_{45}$ and $A \beta_{42}$. Normally, secreted soluble "short $A \beta$ " peptides of 40 or less residues are rapidly degraded. Site of mOC78 antibody recognition sequence for aggregated $A \beta$ shown at residues 9-13. Below, stimulation of endocytosis of $A \beta P P$ is promoted with 1) BACE cleavage of A $\beta P P$ to CTF1-99 at plasma membrane or 2) in endosome. 3) Subsequent processing by gamma-secretase cleavage of CTF99 into $A \beta, 4)$ long $A \beta$ forms aggregate in the membrane or in the lumen of late endosomes, 5) further aggregation leads to accumulation inside the endosome or endolysosome. Organelle markers are shown for co-localization studies. Separately, $A \beta$ forms are associated with mitochondria and macroautophagy with markers for these compartments.

AD: they lead to an increase in intraneuronal long $\mathrm{A} \beta \mathrm{s}$, implicating them as key players in pathogenesis. Intraneuronal amyloid is a complex mixture of insoluble amyloid- $\beta$ protein precursor (A $\beta P P)$ carboxyl terminal fragments and $A \beta$ species [9-13], reviewed in [14]. This material is aggregated in the same manner as amyloid aggregates because it reacts with a variety of aggregation-specific antibodies [15-17]. The accumulation of intraneuronal amyloid appears to be critical for neuritic plaque formation because treatment of 5xFAD mice with a CSF1R inhibitor that ablates microglia blocks intraneuronal amyloid accumulation and the subsequent deposition of neuritic plaques [18]. Here we report direct evidence for the acummulation of intraneuronal long $A \beta s$ as a function of age, endocytosis, and excitotoxicity.

We have proposed a modified amyloid hypothesis that the intraneuronal amyloid contains "long" $\mathrm{A} \beta$ species ending at residues 45 to 49 that arise as a result of incomplete carboxy terminal trimming activity of gamma-secretase (Fig. 1) [17]. Although the standard model of the amyloid cascade hypothesis favored the view that soluble secreted $A \beta$ is the central player in $\mathrm{AD}$, the same facts support an alternative model that postulates a pathogenic role for intracellular aggregated $A \beta$ (iA $\beta$ ), longer fragments of $A \beta P P$ containing the $A \beta$ sequence, collectively named "long $A \beta s$ ". We hypothesize that long $A \beta$ isoforms such as $A \beta_{45}$ remain and aggregate inside neurons and are not secreted, in contrast to $A \beta_{42}$, which is preferentially, though not exclusively secreted (Fig. 1).

Many assume that a lifelong buildup of extracellular amyloid or reactive oxygen species (ROS) damage eventually reaches a clinical threshold for dementia. However, neither mouse models nor human antiamyloid or anti-oxidant therapies have validated this assumption. We have proposed that metabolic adaptation to a sedentary lifestyle impairs mitochondrial function with less energy for healthy management of amyloid and tau proteostasis, synaptic function, inflammation [18], ROS, and other stressors. This Epigenetic Oxidized Redox Shift (EORS) theory of aging postulates that an age-related oxidized redox shift causes a metabolic shift, epigenetic changes and a futile cycle of declining capacity with age $[19,20]$. Here, we hypothesize that these changes increase $A \beta$ processing and intracellular aggregation. We examine these changes in $\mathrm{iA} \beta$ at the single-cell level.

To elucidate the age-related processing of these forms, we cultured neurons from adult brains of the $3 \times T g-A D$ mouse, compared to non-transgenic neurons in which synthesis and processing of $A \beta P P$ is naturally driven. This transgenic model incorporates human mutations for accelerated overproduction of $\mathrm{A} \beta$, yet memory impairment is delayed for many months. Our methods provide uniform conditions for comparing epigenetically enforced, age-related changes, removed from individual variations in hormones, vasculature, and the immune system. This allowed us to address the largest risk factor for $\mathrm{AD}$, age. Here we report that $i A \beta$ contains long $A \beta_{45}$ and its accumulation in mitochondria, endosomes, and autophagosomes is dramatically increased with aging and upon glutamate treatment.

\section{MATERIALS AND METHODS}

\section{Mouse models}

We used the triple transgenic mouse model of $\mathrm{AD}(3 \mathrm{xTg}-\mathrm{AD})$ with human transgenes A $\beta P P($ Swe, KM670/671NL) and Tau (P301L) under the control 
of Thy1.2 promotors in a PS1 (M146V) transgenic mouse [21]. The mice were housed 1 to 5 per cage and fed rodent diet 2020X (Envigo Teklad, Placentia, CA) with $24 \%$ calories from protein, $16 \%$ from fat, and $60 \%$ from carbohydrates). Room temperature was controlled at $70^{\circ} \mathrm{F}$, humidity at 16-25\% with a 12-h light dark cycle. Non-transgenic controls were C57/BL6, bred in house but obtained originally from Charles River (San Diego, CA). The 5XFAD (B6SJL-Tg(AßPPSwFILon,PSEN1*M146 L*L286V)6799Vas/Mmjax) mice from The Jackson Laboratory [22] were genotyped by qPCR (automated genotyping using human $\mathrm{A} \beta \mathrm{PP}$ and PS1 primers, TransnetYX, Cordova, TN) to ensure expression of comparable levels of the human A $\beta P P$ and PS1 genes.

\section{Primary neuron culture}

$1 \mathrm{~mL}$ isoflurane, USP (Piramal Healthcare, Bethlehem, PA 66794-013-25) was used to anesthetize the mice. Adult hippocampal and overlaying cortical neurons were isolated separately from female or male young (2, 4, and 6 months), middle-age $(9,10$, and 11 months) and old (21 months) nTg and 3xTg-AD mice [23]. The combined hippocampus and overlying frontal cortex of each hemisphere were sliced at $0.5 \mathrm{~mm}$ and combined in Hibernate AB (BrainBits LLC, Springfield, IL, \#HAB 500) and placed into $30^{\circ} \mathrm{C}$ bath for $8 \mathrm{~min}$. The tissue was digested with $2 \mathrm{mg} / \mathrm{ml}$ papain (Worthington, Lakewood, NJ, LS003119) in Hibernate A minus Calcium (BrainBits HACA) and $0.5 \mathrm{mM}$ Glutamax (Thermo Fisher, Waltham, MA, 35050-061) for $30 \mathrm{~min}$ in $30^{\circ} \mathrm{C}$ dry bath while shaking at $170 \mathrm{rpm}$. The slices were triturated, and each hippocampus and hemicortex was transferred to a separate $15 \mathrm{~mL}$ tube of Optiprep (Cosmo Bio, Carlsbad, CA, AXS-1114542) of 4 layered densities. The two gradients were centrifuged at $800 \mathrm{~g}$ for $15 \mathrm{~min}$. The neuron enriched fractions were collected and transferred to $5 \mathrm{~mL}$ of Hibernate $\mathrm{AB}$. The cell suspension was centrifuged twice for $1 \mathrm{~min}$ at $200 \mathrm{~g}$ and the supernatant was discarded. The cells were plated onto Poly-D-lysine (SigmaAldrich, St Louis, MO, P6407-5MG) coated $12 \mathrm{~mm}$ coverslips (Carolina Biologicals, Burlington, NC, 41001112) at 50,000 cell $/ \mathrm{cm}^{2}$ in Neurobasal plus with B27 plus (Thermo Fisher A3653401) supplemented with $5 \mathrm{ng} / \mathrm{mL}$ each mouse FGF2 (Thermo Fisher, PMG0035 or Pepro-Tech 450-33) and PDGFBB (PMG0045 or Pepro-Tech 315-18) for trophic support. The medium was adjusted from 235 to 270
mOsm with $5 \mathrm{M} \mathrm{NaCl}$. One-half medium changes were made on days 4 and 7 with $10 \mathrm{ng} / \mathrm{mL}$ growth factors, assuming consumption of the prior growth factors. The cells were cultured for 10-15 days at $37^{\circ} \mathrm{C}$ in $5 \% \mathrm{CO}_{2}$ and $9 \% \mathrm{O}_{2}$ at saturated humidity (Thermo-Forma, Marietta, OH, Model 3130). Quality control was maintained above $80 \%$ viability at all time points in about $90 \%$ of cultures by a live-dead assay.

\section{Live-dead assay}

The live neurons on glass coverslips were stained with fluorescein diacetate $(15 \mu \mathrm{g} / \mathrm{mL}$; SigmaAldrich, F7378) and propidium iodide $(4.6 \mu \mathrm{g} / \mathrm{mL}$; Sigma-Aldrich, P4170) [24]. After 2 min of incubation, the cells were rinsed once with Hibernate A Low Fluorescence (BrainBits LLC, HALF), and the wash was saved so the suspended dead cells could also be examined. Images were taken with the fluorescent microscope Olympus IX83 at 20X magnification for green (live) and red (dead) fluorescence. Viability was calculated as the average percent live divided by the total adherent cells (live + dead) in 10 adjacent fields, added to non-adherent dead cells.

\section{Polyclonal serum against $A \beta_{45}$}

A peptide corresponding to residues $36-45$ of the A $\beta / A \beta P P-C T F 99$ sequence (VGGVVIATVI) was synthesized and coupled to keyhole limpet hemocyanin via its amino terminus using disuccinimidyl suberate (DSS, Thermo Fisher 21555) according to the manufacturer's instructions. Two New Zealand white rabbits were immunized with $1 \mathrm{mg}$ of the resulting antigen in incomplete Freund's adjuvant and boosted at monthly intervals and bled according to an IACUC approved protocol under contract with ProMab Biotechnologies, Richmond, CA. We also immunized rabbits with 10 residue peptides corresponding to the carboxyl terminus of $A \beta$ ending at residues $46,47,48$, and 49 , but these immunizations did not result in a detectable, specific immune response (data not shown). The specificity of the resulting antisera from bleed 4 was determined by spotting $1 \mu \mathrm{g}$ of $A \beta_{40}, A \beta_{42}, A \beta_{36-45}, A \beta_{37-46}$, $A \beta_{38-47}, A \beta_{39-48}, A \beta_{40-49}$, and a bridging peptide corresponding to $A \beta_{36-54}$. $A \beta_{45}$ specific antibodies were affinity purified by passing the serum over a column of the bridging peptide $A \beta_{36-54}$, adsorbing the eluate on a column of $A \beta_{36-45}$ and eluting the bound antibody with $0.2 \mathrm{M}$ glycine, $\mathrm{pH}$ 2.3. The eluted anti- 
body was rapidly neutralized with $10 \mathrm{mM}$ Tris buffer, $\mathrm{pH} 8.0$ and stored at $4^{\circ} \mathrm{C}$.

\section{Immunocytochemistry}

The cultured neurons attached to glass coverslips were fixed with 4\% paraformaldehyde (Electron Microscopy Science, Hatfield, PA, 19200) in Dulbecco's phosphate buffered saline minus calcium (Thermo Fisher, 14190-144) for 10 min. A blocking buffer containing 2\% Bovine Serum Albumin (Sigma-Aldrich, SLBT0168), 0.5\% Triton X-100 (Sigma-Aldrich, X100-100ML) in DPBS minus Ca was added to the coverslips for $1 \mathrm{~h}$. Table 1 lists the primary antibodies used and their dilutions in antibody dilution buffer (ABD, $1 \%$ bovine serum albumin (BSA), $0.05 \%$ Triton $\mathrm{X}-100$ in DPBSCA): anti-MAP2 for characterizing neurons, $\mathrm{mOC} 78$ [16] for oligomeric amyloid fibrils, anti-Ab45 for long $A \beta$ protein with residue 45 at the $C$-terminus, anti-cathepsin D for lysosomes [25], anti-Rab7a for endocytic vesicles [26, 27], anti-cytochrome $\mathrm{C}$ for mitochondria [28] and anti-p62 for autophagosomes [29]. The primary antibodies were allowed to bind over night at $4{ }^{\circ} \mathrm{C}$. Secondary antibodies were diluted in antibody dilution buffer (1\% BSA, $0.05 \%$ Triton X100 in PBS) and were allowed to bind for $1 \mathrm{~h}$ at room temperature. As a specificity control, we expressed a fusion protein consisting of the carboxyl terminus of GST fused to the amino terminus $A \beta_{45}$ in E. coli and purified the fusion protein on glutathione agarose beads. The conjugate (1:250) was mixed with primary anti-A $\beta_{45}$ (1:1000) for specific adsorption immediately before binding to neurons.

The stained slips were washed 3 times in antibody dilution buffer with 5 min between each wash. The nuclei were stained for $2 \mathrm{~min}$ with $1 \mathrm{ng} / \mathrm{mL}$ bisbenzamide (from a $1 \mu \mathrm{g} / \mathrm{mL}$ stock, Sigma-Aldrich, B 1155). The stained coverslips were mounted on glass slides using 1 drop of Aqua-Mount (Thermo Fisher, 13800).

The stained coverslips were imaged using an Olympus IX83 epi-fluorescent microscope with 60X oil-immersion objective using Olympus dichroic filters for DAPI (bisbenzamide), GFP (Cathepsin D, MAP2, Alz50 or Rab7), and RFP (mOC78 or Ab45). Images were collected by a Retiga Exi camera (12-bit resolution, CCD; QImaging, Surrey, BC, Canada) controlled by Metamorph software (Molecular Devices, San Jose, CA). Illumination, exposure times, camera gain were held constant for each single experiment within each antibody, but exposures were different for detection of each color, avoiding saturation. Image J v1.51n (NIH, Bethesda, MD) software was used for analysis of fluorescence images. Background fluorescence was first removed from all images with a rolling ball radius of 20 pixels. Minimum threshold was set to minimize objects from samples with the primary antibodies omitted. Integrated density per cell was the area of fluorescent objects multiplied by their intensity per field divided

Table 1

Antibodies used for immunocytology

\begin{tabular}{|c|c|c|c|}
\hline Antibody & Type & Source & Dilution \\
\hline \multicolumn{4}{|l|}{ Primary antibodies } \\
\hline Anti-mOC78 & $\begin{array}{l}\text { Rabbit monoclonal } \\
\text { Residues 8-11(SGY), 20-24(FEV) }\end{array}$ & {$[17,30]$} & $1: 40$ \\
\hline Anti-A $\beta_{45}$ & $\begin{array}{l}\text { Rabbit affinity purified } \\
\text { polyclonal }\end{array}$ & this work & $1: 1000$ \\
\hline Anti-A $\beta P P$ CTF Rabbit polyclonal & $\begin{array}{l}{[17]} \\
\text { Residues } 676-695 \text { of A } \beta \text { PP695 }\end{array}$ & $1: 1000$ & \\
\hline Anti-amyloid 6E10 & $\begin{array}{l}\text { Mouse monoclonal } \\
\text { Residues 5-7 }\end{array}$ & $\begin{array}{l}\text { Covance Signet } \\
{[30]}\end{array}$ & $1: 1000$ \\
\hline Alz-50 & Mouse monoclonal & {$[31,32]$} & $1: 20$ \\
\hline Anti-Rab5a & Mouse monoclonal & Sigma-Aldrich (R7904) & $1: 100$ \\
\hline Anti-Rab7a & Mouse monoclonal & Sigma-Aldrich (R8779) & $1: 500$ \\
\hline Anti-Cathepsin D & Mouse monoclonal & Calbiochem (IM03) & $1: 100$ \\
\hline Anti-MAP2 & Mouse monoclonal & Sigma-Aldrich (M4403) & $1: 250$ \\
\hline Anti-cytochrome $\mathrm{C}$ & Mouse monoclonal & BD Bioscience (556432) & $1: 1000$ \\
\hline Anti-p62 & Mouse monoclonal & $\begin{array}{l}\text { Novus Biologicals } \\
\text { (NBP2-23490) }\end{array}$ & $1: 500$ \\
\hline \multicolumn{4}{|l|}{ Secondary antibody conjugates } \\
\hline Anti-mouse & Goat anti-mouse & & \\
\hline \multirow{3}{*}{ Anti-rabbit } & Alexafluor488 & Thermo Fisher (A11029) & $1: 2000$ \\
\hline & Donkey anti-rabbit & & \\
\hline & AlexaFluor555 & Thermo Fisher (A31572) & $1: 500$ \\
\hline
\end{tabular}


by the number of neurons in that field. The number of fluorescent objects/cell and their size was also analyzed. Co-localization with automatic thresholding (Image J, FIJI version) is based on a pixel by pixel measure of the Pearson correlation of intensities after automatic subtraction of pixels with zero correlation $[33,34]$. Pixel size was $0.012 \mu \mathrm{m}^{2}$ with a minimum of 3 pixels $\left(0.036 \mu \mathrm{m}^{2}\right)$ above threshold to count as an object. Note that endosomes and lysosomes are $0.01-0.16 \mu \mathrm{m}^{2}$ in cross section [25].

\section{Statistics}

Results are presented as mean and standard error. Statistical significance was determined by using single factor ANOVA with significance considered at $p<0.05$. Follow-up Fisher's exact $t$-tests were adjusted for repeated measures (Pro-Stat, Pearl River, NY). File names provided with each figure allow tracing to original data files for authentication.

\section{RESULTS}

\section{Characterization of "long" A $\beta$ antibody and intraneuronal staining}

In order to test the hypothesis that long $A \beta$ s accumulate intraneuronally (iA $\beta$ ), we immunized rabbits with the 10-residue peptide of the $A \beta$ sequence ending at residue 45. By immunofluorescence of brain sections with affinity purified IgG from this serum (Fig. 2A, B), iA $\beta_{45}$ was seen in most of the hippocampal neurons in a 2-month-old 5xTg-AD mouse and much less in nTg mice. These neurons also stained with the commonly used 6E10 for residues N1-16 which could tag the commonly reported $A \beta_{40}$, $A \beta_{42}$, or CTF. The serum directed against $A \beta_{45}$ reacted specifically with only the antigenic peptide ending at residue 45 (Fig. $2 \mathrm{C}$ ) and not $A \beta_{42}$ or any of the longer peptides in dot blots (Fig. 2D). Specificity was demonstrated by decreased staining after adsorption of the $A \beta_{45}$ antiserum with an $\mathrm{A} \beta_{45}$-GST conjugate (Fig. 2E, F). We will use this novel end-specific antiserum against longer $A \beta_{45}$ and a conformation dependent, aggregation specific monoclonal mOC78 to monitor iA $\beta$ accumulation $[17,30]$.

\section{Age increases iA $\beta$ accumulation in adult neurons}

We compared the effect of age on the intracellular abundance and distribution of $A \beta_{45}$ immunoreac- tivity (iA $\beta_{45}$ ) by isolating and culturing neurons from $3 \times \mathrm{Tg}-\mathrm{AD}$ mice of different ages. We wanted to determine if age from which neurons were isolated had a differential effect on iA $\beta_{45}$ levels. Coincident processing of neurons from 4- and 11-month-old middle-age male mice indicated a 30 -fold increase in iA $\beta_{45}$ immunoreactivity compared to 4-month neurons (Fig. 2G-I). This difference was exhibited with similar neurite outgrowth at these two ages (Supplementary Figure 1), as previously shown [35-37]. We note that the objects per cell are low numbers as a result of fixed scaling for comparison of bright objects in both the 4- and 11-month neurons.

\section{Parallel log-log distribution of mOC78 imaged particle sizes in 3xTg-AD and non-Tg neurons}

mOC78 reacts with aggregates of $A \beta$, but not with A $\beta P P[9,17,30]$. The epitope for mOC78 maps to residues 8-11 (SGYE) of $A \beta$, but immunoreactivity is strongly dependent on aggregation and common to amyloid fibrils from unrelated sequences, suggesting a generic amyloid epitope [23]. Although mouse $\mathrm{A} \beta$ contains an $\mathrm{F}$ residue at position 10 instead of a $\mathrm{Y}, \mathrm{mOC} 78$ binds equally well to peptides containing an $\mathrm{F}$ instead of $\mathrm{Y}(\mathrm{SG}(\mathrm{Y} / \mathrm{F}) \mathrm{E})$ [Reyes-Ruiz and Glabe, manuscript in preparation). We wanted to determine whether there was a principle size class of iA $\beta$ aggregates driven by their aggregation or compartmentalization and how the particles related to organelles involved in intracellular uptake and turnover of plasma membrane proteins such as A $\beta P P$ and its fragments. Figure $3 \mathrm{~A}$ shows the abundance of red punctate mOC78 immunoreactivity in neurons from a $3 \times \mathrm{Tg}-\mathrm{AD}$ mouse compared to considerably lower intensities from a non-Tg control (Fig. 3B), while the green Rab-7 co-labeling for late endosomes $[38,39]$ were similar. By enhancing gain of the nonTg image in Fig. 3C, we can also see red mOC78 immunoreactivity that was present as far lower intensity (concentration). The increased gain in Fig. 3C of the same non-Tg field in Fig. 3B results in the visualization of similar size mOC78-immunoreactive particles to those in the $3 \times \mathrm{Tg}$-AD neurons and suggests that they were present from endogenous $A \beta$ at a much lower concentration in the non-Tg neurons and that the size distribution does not depend on the overexpression of the transgenes. Surprisingly, Fig. 3D shows that the distribution of mOC78 imaged particle sizes was not gaussian but fit well to a log-log distribution. The slopes from sizes of 0.1 to $2 \mu \mathrm{m}^{2}$ fit within $1 \%$ of each other, but particles in $3 \times \mathrm{Tg}$-AD neurons 


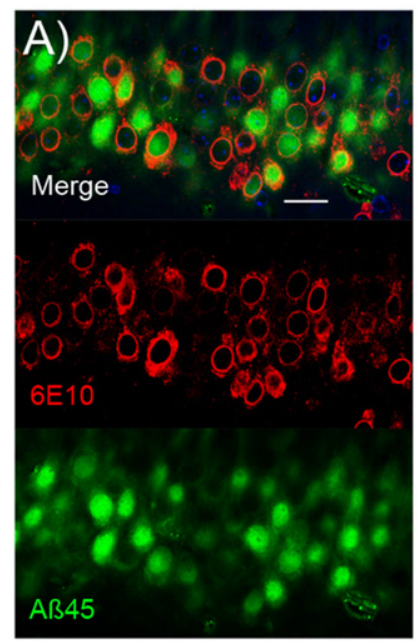

B)

C) 36 VGGVVIATVIVITLVMLKKK 54

G)

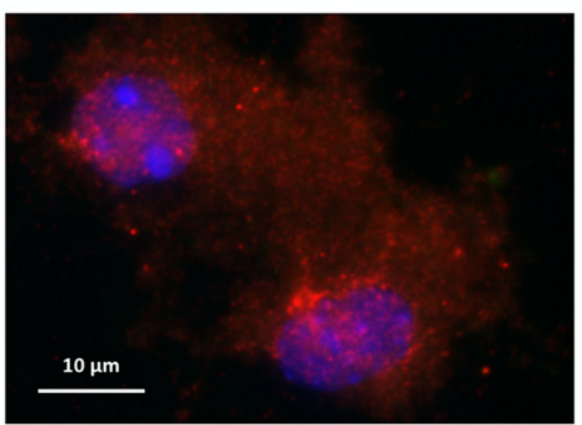

H)

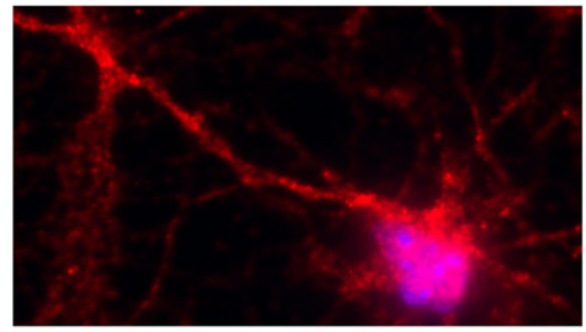

D)

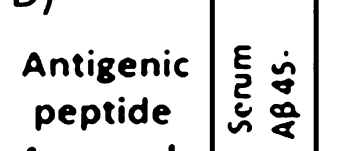

$A \beta 1.42$

$A B 1.40$

$A B 36.54$

\begin{tabular}{|l|l|}
\hline$A B 36.05$ & $\bullet$ \\
\hline
\end{tabular}

$A B 31.46$

$A B 38.47$

$A B 39.48$

$A B .00 .89$

E) Intensity / Cell

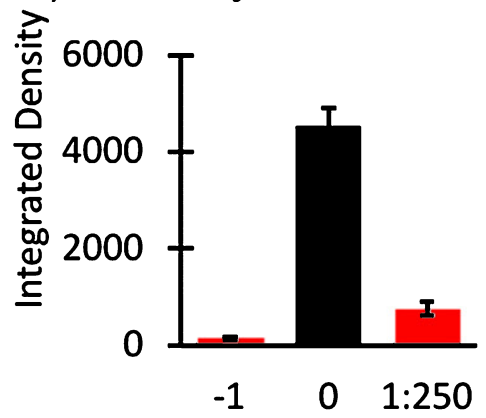

F) Objects / Cell

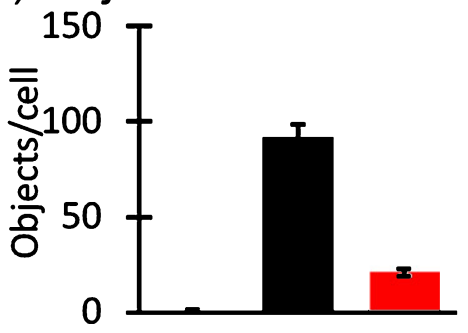

$\begin{array}{lll}-1 & 0 & 1: 250\end{array}$ GST-Aß45
I) $=^{50000} \mp \quad$ Ab45 Intensity/Cell
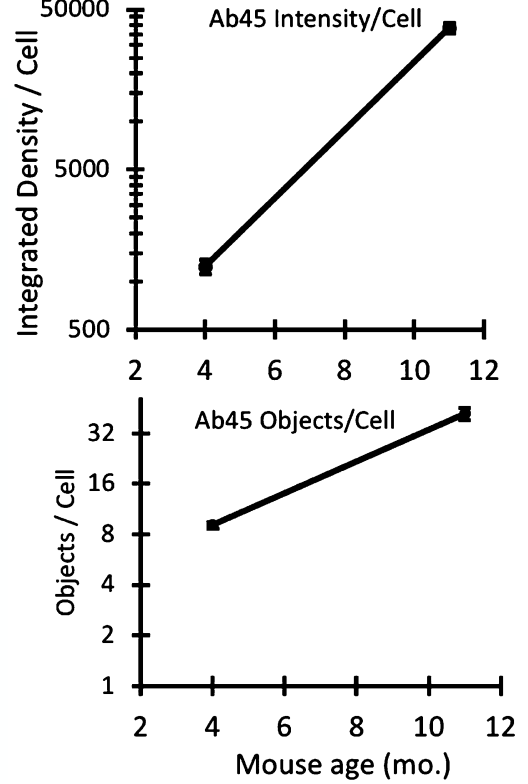

Fig. 2. Prominent long form of intracellular $A \beta_{45}$ increases with age of neurons. A new C-terminal antiserum identified iA $\beta_{45}$ (red) compared to N-terminal 6E10 (green) in CA1 of A) 2-month-old 5xTg-AD and B) 14-month-old non-Tg mouse. C) A $\beta P P$ sequence from residues 36-54 of the A $\beta$ sequence with residues 41-45 underlined. D) Specificity of serum A $\beta_{45}$ for only its own antigenic peptide on dot blot. E) Competitive antigen adsorption of the $A \beta_{45}$ antiserum: -1 is no $A \beta_{45}$ antiserum, just secondary antibody; 0 is $A \beta_{45}$ antiserum with no antigen adsorption; 1:250 is dilution of GST-A $\beta_{45}$ conjugate premixed with $\mathrm{A} \beta_{45}$ antiserum before binding to cells $(n=33-47$ cells, file 180608). G) $A \beta_{45}$ immunoreactivity in 4-month-old male 3xTg-AD neurons compared to $\mathrm{H}$ ) neurons from an 11-month-old mouse cultured at the same time and co-processed. I) Average integrated intensity of iA $\beta_{45}$ immunoreactivity per cell and objects per cell with age. Note $\log$ scale. Control staining for neurons treated without primary antibody was a density of 113 and 0.2 objects per cell for 4-month neurons; for 11-month neuron density was 442 and 0.1 objects per cell $(\mathrm{N}=35-79$ cells each; standard error bars are slightly larger than symbols, file 180329). 
A) $3 \times \operatorname{Tg} \mathrm{mOC78} \quad \operatorname{Rab} 7$

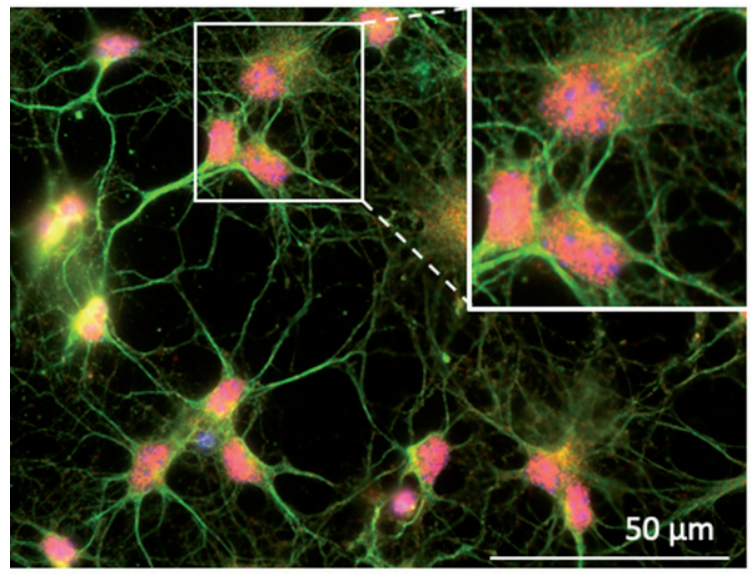

B) Ntg same settings as $A$

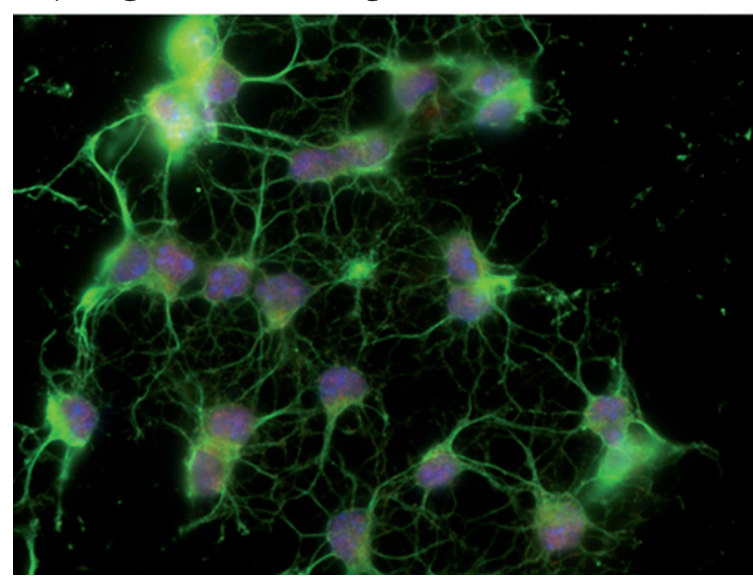

C) Ntg - maximized mOC78 settings

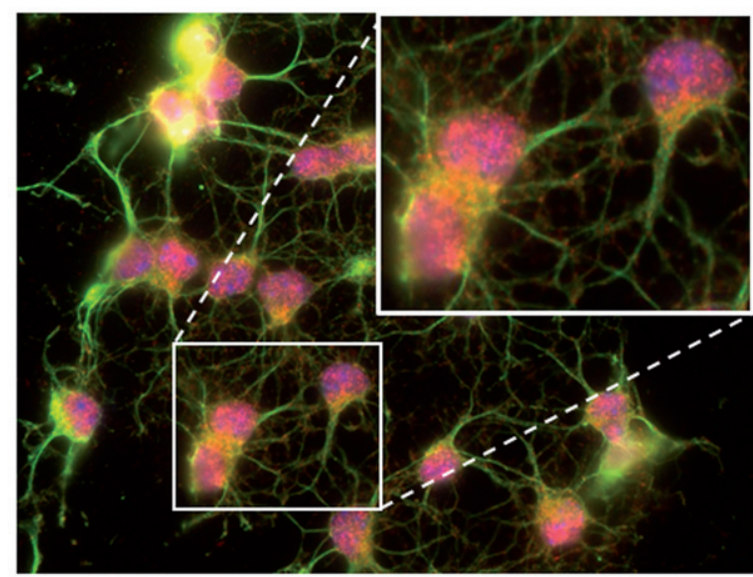

D) mOC78 size distributions

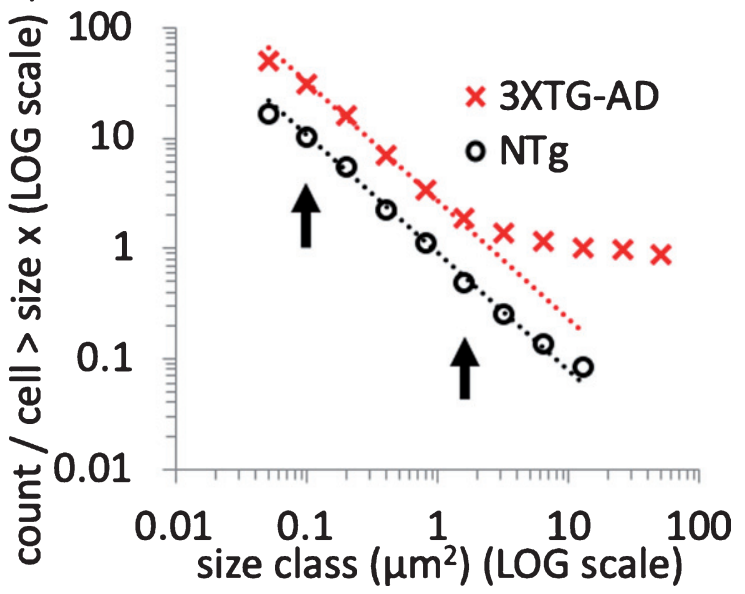

Fig. 3. Parallel distributions of intracellular mOC78 amyloid imaged particle sizes in neurons from 3xTg-AD and non-Tg (NTg) mice. A) Neurons from a male 11-month-old 3xTg-AD mouse stained with mOC78 (red), Rab7 (green), and bisbenzimide (blue). Enlarged field is $55 \mu \mathrm{m}$ wide. B) Neurons from a male 11-month-old non-Tg mouse cultured and stained at the same time and imaged at the same settings as in A. C) Same field as B, but with gain increased to better visualize mOC78 particle sizes. Enlarged field is $46 \mu \mathrm{m}$ wide. D) Distribution of mOC78 particle sizes on log-log scale. Data was log-binned and least squares fit over the range indicated by arrows. $3 \times \mathrm{Tg}$-AD from 79 cells, 3899 particles, fit to count $/$ cell $=0.430 * 10 \wedge(-1.073 *$ size $), \mathrm{R}^{2}=0.999$; non- $\mathrm{Tg}$ from 96 cells, 1593 particles fit to count $/$ cell $=-0.050$ * $10 \wedge(-1.067 *$ size $), \mathrm{R}^{2}=0.998$. File 180511

were 8 times more abundant, due to the overexpression of AßPP genes in these mice. This size range fits with the size of lysosomes and endosomes [25]. The yellow in Fig. 3 indicates overlap of the mOC78 and the Rab-7 stains, suggesting that mOC78 accumulates in late-endosomes. Notice also that the size range of mOC78 immunoreactive particles for the $3 \times \mathrm{Tg}-\mathrm{AD}$ neurons extends to the size of the whole neuron, nearly $100 \mu \mathrm{m}^{2}$ (Fig. 3D). The marked deviation from linearity at approximately $2 \mu \mathrm{m}^{2}$ suggests the termination of a normal mechanism of formation that exceeds the cell's ability to degrade these iA $\beta$ objects. Below (Fig. 8), we specifically address quan- titative analysis of autophagic co-localization with various $A \beta$ forms.

\section{Alz-50 tau, $A \beta_{45}$, and $\mathrm{mOC} 78$ \\ immunoreactivities are stimulated by glutamate}

Memantine is approved by the FDA for treatment of $\mathrm{AD}$. It acts as an uncompetitive antagonist of glutamate binding to NMDA receptors [40]. In AD, excess glutamate is postulated to cause intracellular calcium overload [41], reductions in AMPA receptors GluR1 and GluR2/3 in CA1 with increased density in the dentate gyrus [42], decrements in glutamate re-uptake 
[43], and metabotropic receptor activation [44]. Here we compare the effects of short-term $(2 \mathrm{~h})$ glutamate exposure on a pathology-related conformer of tau aggregation detected with the Alz-50 antibody [31, 32], mOC78, and $i A \beta_{45}$. Short-term glutamate treatment produced a large increase in red $\mathrm{iA} \beta_{45}$ deposits in neurons from an old 3xTg-AD brain (Fig. 4A-C). In the neurons treated with glutamate for only $2 \mathrm{~h}$, Alz-50 tau immunoreactivity greatly increased and redistributed into dendrites (Fig. 4A, B, D). Glutamate rapidly increased the density of $i \mathrm{~A} \beta_{45}$ per cell 4-fold while the Alz-50 density increased 2-fold. In another experiment, with neurons from a middle-age $3 \times T$ Tg-AD brain (Fig. 4E, F), we also saw strong colocalization of mOC78 with Alz-50. Treatment with glutamate increased both markers and altered the Alz50 distribution into dendrites, where others have seen neurofibrillary tangles by electron microscopy [45, 46]. Figures 2 and 3 showed data for male neurons. The experiments in Fig. 4 involved neurons from female mice. Comparison of male to female expression of mOC78 indicated only small differences that scaled with Rab7 immunoreactivity (Fig. 5). Since mOC78 male measures were increased over females in proportion to the mass effect of sex on Rab7, these results suggest that sex is not a major factor in the $\mathrm{iA} \beta$ accumulation of mOC78 immunoreac- tivity. With the age-dependence of $A \beta_{45}$ production (Fig. 2) and its exacerbation by glutamate (Fig. 4), we inquired how age and glutamate affected the larger aggregates of mOC78. Figure $6 \mathrm{~A}$ and $\mathrm{B}$ show relative amounts of mOC78 immunoreactivity increased exponentially (50-fold) with age with age from 4 to 21 months. In old age, many large mOC78 aggregates greater than $1 \mu \mathrm{m}^{2}$ were seen (arrows in Fig. 6A). A brief treatment with glutamate increased mOC78 density per cell in the young and middle-age neurons but less so in neurons from old mice. The distribution of object sizes followed a log-log distribution so that mean size was not a relevant statistic (Fig. 6C). Instead, for 21-month neurons the calculated slope of object size was $20 \%$ lower and intercept $20 \%$ higher compared to 11-month size distributions. For small objects, mOC78 size was similar for 11- and 21month neurons, suggesting a similar mechanism of formation. For larger objects above $1 \mu \mathrm{m}^{2}$, objects from the old mouse were 2-fold more frequent than those for the 11-month-old mouse (due to a slope $40 \%$ more shallow). With a short glutamate treatment in 21-month neurons, object size grew rapidly with an increase in intercept of 1.8 -fold and a slope $20 \%$ more shallow. These results suggest that age contributes to an increased rate of formation of iA $\beta$ mOC78 immunoreactivity, exacerbated by glutamate and pos-

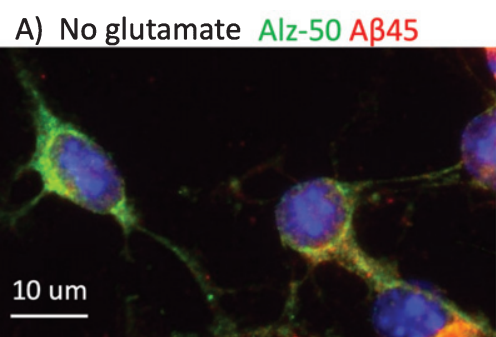

B) + glutamate, $2 \mathrm{hr}$.

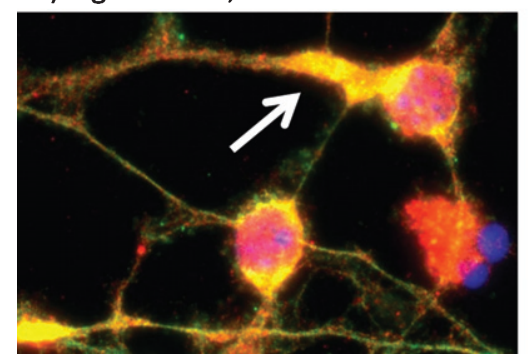

C) $A \beta 45$

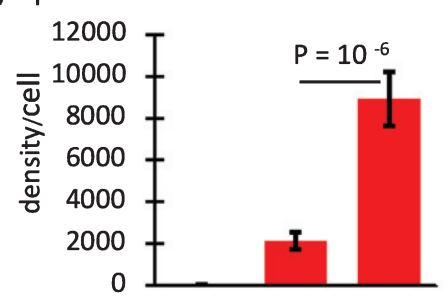

D) Alz-50

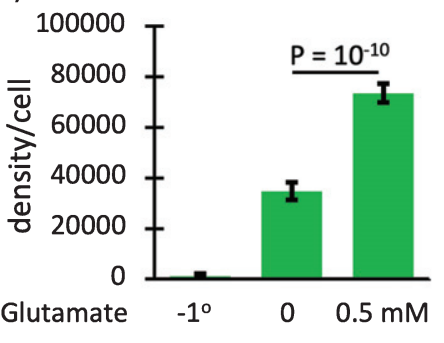

E) moc78, Alz50, no glutamate

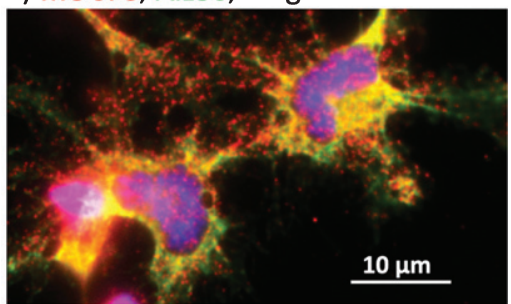

F) + glutamate, $2 \mathrm{hr}$.

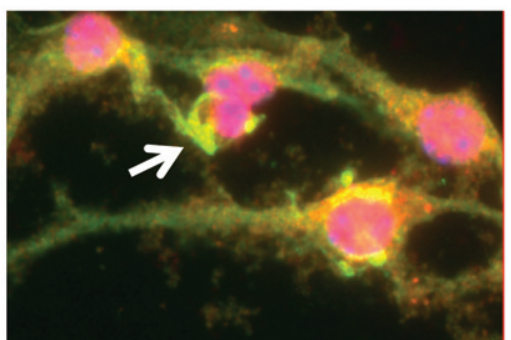

Fig. 4. Large increase in $A \beta_{45}$ and Alz-50 with glutamate with relocalization of Alz-50 tau to dendrites. A) Alz-50 tau in axons and soma (green) with low $\mathrm{A} \beta_{45}$ puncta (red) B) increases with $2 \mathrm{~h}$ treatment with $0.5 \mathrm{mM}$ glutamate and moves to dendrites (arrow), with colocalization to anti-A $\beta_{45}$ puncta in 23-month-old male $3 \times \mathrm{Tg}$-AD neurons. C) 4-fold increase in $\mathrm{A} \beta_{45}$ with glutamate exceeds $\mathrm{D}$ ) 2-fold increase in Alz-50. $\mathrm{N}=17-35$ cells. File 170406. E) 10-month-old female neurons rescaled to show individual mOC78 objects and overlap with Alz-50. F) Increase in mOC78 with glutamate treatment and large objects resembling neurofibrillary tangles (arrow). 10-month-old female 3xTg-AD neurons. File 170726. 
A) mOC78 i) density

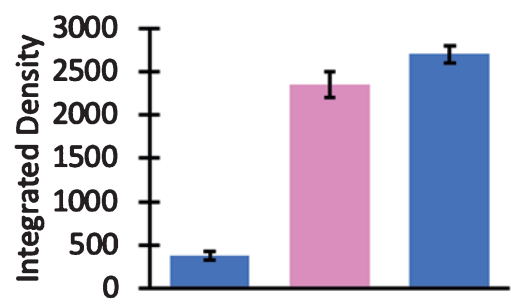

B) Rab7 i) density

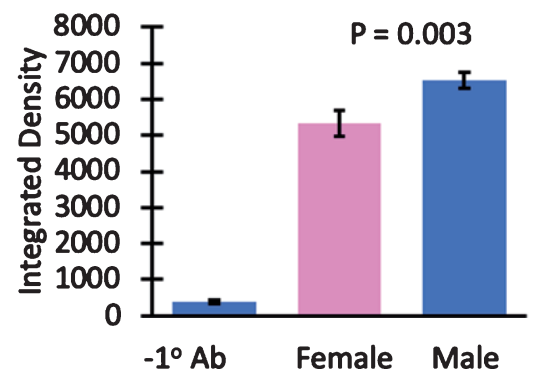

ii) count

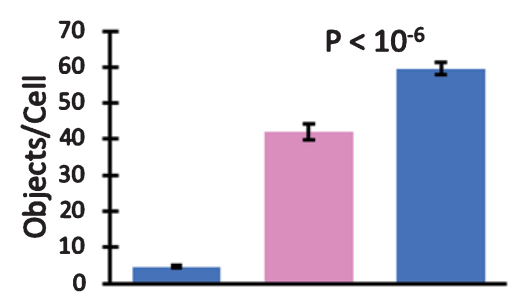

ii) count

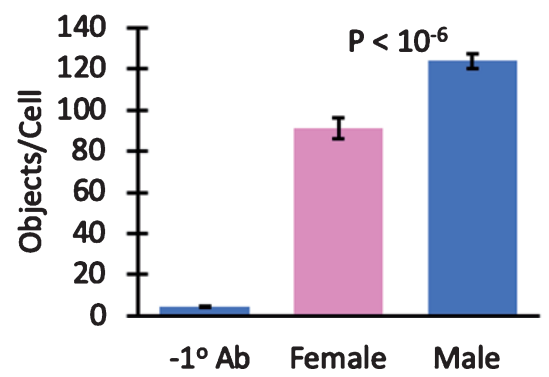

iii) area

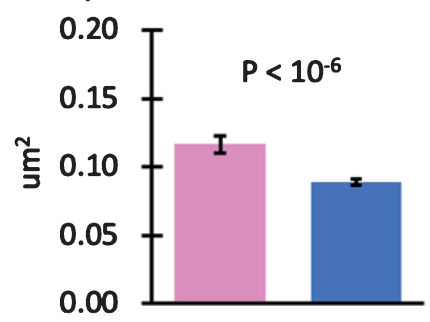

iii) area

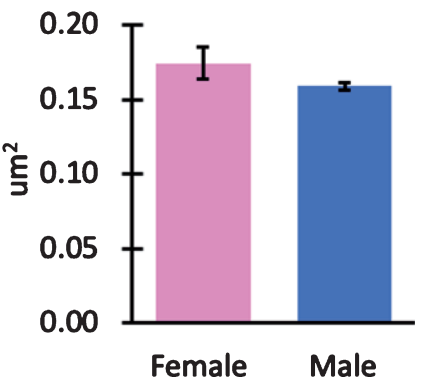

Fig. 5. Small effect of mouse gender on mOC78 and Rab7 immunoreactivity. Male to female comparisons of A) mOC78 and B) rab7 immunoreactivity in neurons from 4-month-old mice. i) integrated density; ii) object counts/cell; iii) area per object. We have reported results from both male and female mice. To determine how dependent the results were on gender, in one experiment we explicitly compared mOC78 and Rab7 immunoreactivity in neurons from a female to a male 4-month-old 3xTg-AD mouse. A shows an insignificant $15 \%$ increase in mOC78 immunoreactive density per cell in the male compared to the female. The object counts per cell were $43 \%$ higher in the male with $33 \%$ smaller areas, compared to the female. B shows Rab7 immunoreactive density per cell was $22 \%$ higher in the male compared to the female. The object counts per cell were $36 \%$ higher in the male with only $6 \%$ smaller areas, compared to the female. Colocalization of mOC78 with Rab7 was 0.83 for both sexes. Since mOC78 male measures were increased over females in proportion to the mass effect of sex on Rab7, these results suggest that sex is not a major factor in the iA $\beta$ accumulation of mOC78 immunoreactivity. File 171013.

sibly a decreased rate of clearance (see autophagy studies below).

\section{$A \beta 45$, mOC78, and A $\beta P P-C T F$ colocalize with mitochondria, autophagosomes, endosomes, and lysosomes}

Since the forms of iA $\beta$ processed by autophagy are unclear, we sought to determine the relationship of iA $\beta$ forms to cytochrome $\mathrm{C}$ as a mitochondrial marker, p62 that attaches to LCB3 and ubiquitin of autophagosomes, Rab7a as a marker that links late endosomes to dynein and kinesin molecular motors, and cathepsin D for lysosomes [25]. To be more quantitative than the yellow overlap of merged colors, we correlated pixel intensities between $A \beta$ forms and autophagic markers for cell compartments using the colocalization function in Image J. Correlations of intensities at each pixel can range from no correlation of 0 to 1 for perfect correlation. The threshold for each color is determined automatically. An advantage of this approach is that the degree of correlation is insensitive to the maximum intensity of each color
$[33,34]$. This enabled investigation of which forms of iA $\beta$ collected in specific autophagic organelles, known to be affected in $\mathrm{AD}[45,46]$.

Each $A \beta$ form (mOC78, $A \beta_{45}$, and $\left.A \beta P P-C T F\right)$ most strongly correlated with the late endosome marker Rab-7 (Fig. 7A, G) $(\mathrm{R}=0.82 \pm 0.02, n=7$ cultures (one from Fig. 3), independent of age from 5-11-month-old mice, 2-3 cultures per $A \beta$ form). As expected mOC78 co-localized strongly with the commonly used anti-amyloid antibody $6 \mathrm{E} 10$ ( $R=0.80 \pm 0.02$, data not shown). Importantly, an age-matched control in non- $\mathrm{Tg}$ neurons from a 5month-old mouse showed a similar correlation of $0.89 \pm 0.03$ for mOC78 colocalization with Rab7, despite higher Rab-7 and 5-fold lower mOC78 signal intensity. One of these was from a non- $\mathrm{Tg} 5$-monthold male with an $r=0.89 \pm 0.03(n=58$ cells $)$ and another from an 11-month-old male. In contrast, Fig. 7B shows the correlation of lysosomal cathep$\sin \mathrm{D}$ to decrease from $0.61 \pm 0.03$ for mOC78 to $0.48 \pm 0.05$ for $A \beta_{45}$ and $0.34 \pm 0.02$ for $A \beta P P-$ CTF. We interpret these results as less A $\beta P P-C T F$ reaching fusion with lysosomes than $A \beta_{45}$ and more 
A) Age (mo.) Alz50 mOC78
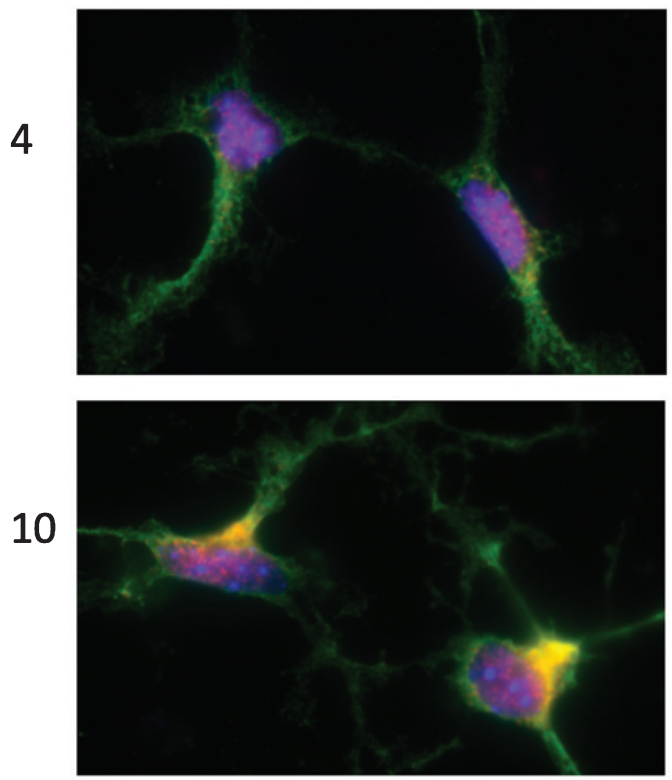

21

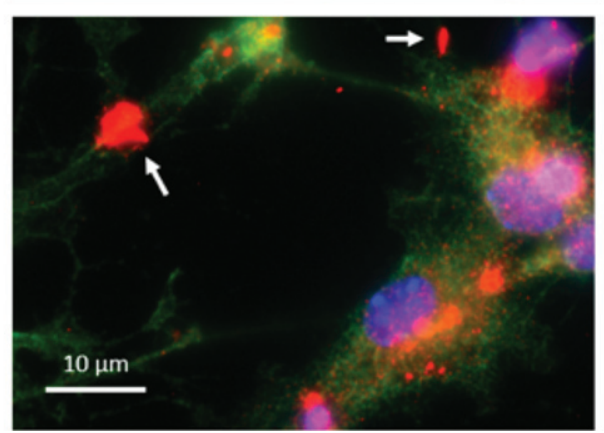

B) mOC78 intensity per cell $(\log )$

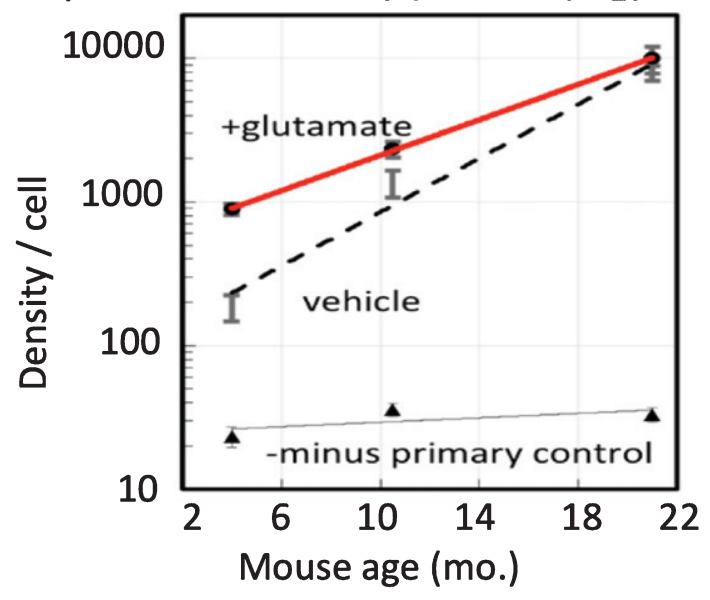

C) mOC78 object size per cell

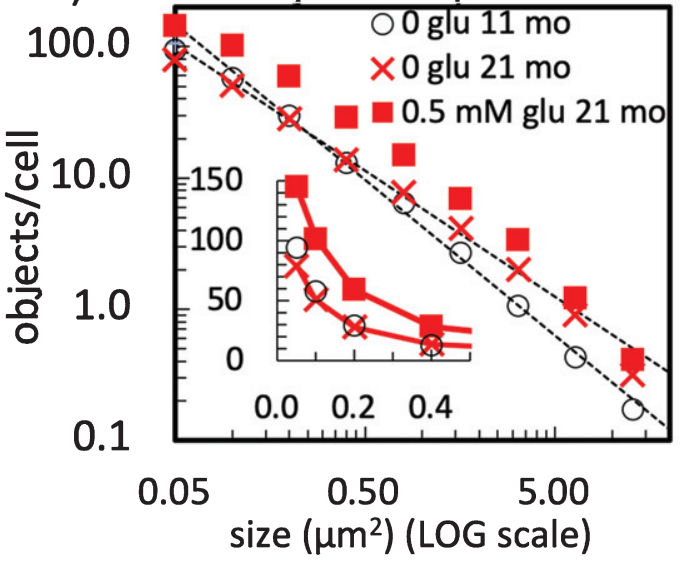

Fig. 6. Exponential deposition of intracellular mOC78 A $\beta$ deposits (red) and misfolded tau (Alz-50 tau, green) with age is accelerated by glutamate. A) Neurons stained and imaged in the same batch, at the same exposure and gain. Neurons from the 21-month-old mouse showed large extracellular deposits of mOC78i immunoreactive material (arrows). B) Exponential relationship of mOC78 increase with age. Zero glutamate: $y=98 * 10^{0.22 x}$; glutamate: $y=511 * 10^{0.14 x}$. C) Increase in mOC78 object size with age and glutamate. Distributions were fit by least squares over the range of 0.1 to $5 \mu \mathrm{m}^{2}: 11$-month objects $=0.634 * 10^{-1.18 * \text { size }}, \mathrm{R}^{2}=0.997,35$ cells, 3306 objects; 21 -month objects $=0.772 * 10^{-0.959 * \text { size }}, \mathrm{R}^{2}=0.998,48$ cells, 4801 objects; 21 -month with $0.5 \mathrm{mM}$ glutamate objects $=1.021 * 10^{-1.053 * \text { size }}, \mathrm{R}^{2}=0.994$, 51 cells, 4807 objects. Inset shows small sizes on a linear scale with large effect of glutamate. Neurons were from female mice of indicated ages. File 170726. Density changes with age confirmed in male as exponential, file 180329.

mOC78 in lysosomal compartments; however, better clearance of AßPP-CTF cannot be ruled out. Overall $\mathrm{A} \beta$ forms were less detectable in lysosomes than the earlier stage of late endosomes. In Fig. 7C and $\mathrm{G}$, the mitochondrial marker cytochrome $\mathrm{C}$ correlated with $\mathrm{A} \beta$ forms at $r=0.71$, almost as strongly with mOC78 as Rab-7. The average of 4 experiments ranging in age from 2 to 11 months, including 1 non$\mathrm{Tg}$ was fairly consistent at $0.73 \pm 0.02$. An example of the strong co-localization is shown in Fig. 7D. Cytochrome $\mathrm{C}$ colocalization with $\mathrm{A} \beta_{45}$ produced a correlation of 0.73 as well $(n=2$, a 5-month-old non-
Tg male and an 11-month-old 3xTg-AD male, files 171005 and 180511, respectively). In Fig. 7E, p62 as a marker of macroautophagy including mitochondrial autophagy was considerably lower at $r=0.37 \pm 0.04$ as exemplified in Fig. 7F and averaged in Fig. 7G. Together these results suggest a strong presence of iA $\beta$ forms in late endosomes and mitochondria with lower levels and sequential processing in lysosomes and autophagosomes from $A \beta P P-C T F$ to $A \beta_{45}$ and then mOC78. They suggest impairment in iA $\beta$ processing in the 3xTg-AD neurons at the level of fusion of late-endosomes with lysosomes. 

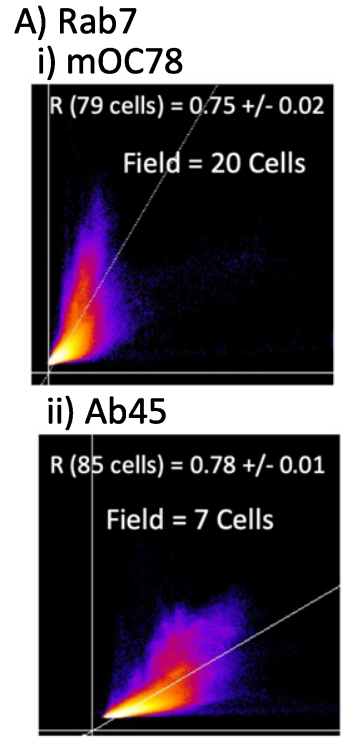

iii) CTF

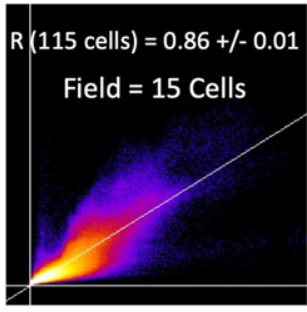

B) Cat D

i) $\mathrm{mOC78}$

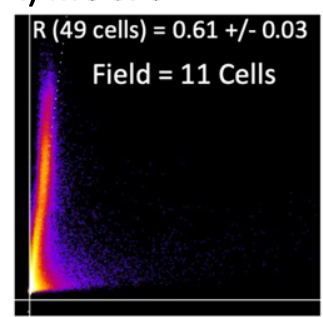

\section{ii) $\mathrm{Ab} 45$}

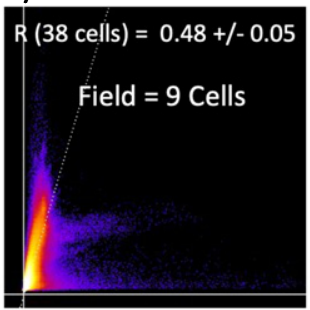

iii) CTF

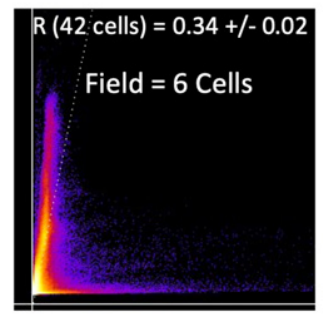

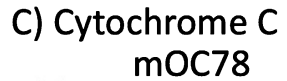

$R(56$ cells $)=0.71+/-0.01$ Field $=19$ Cells

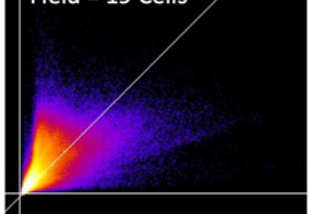

D) Cyt C $\quad \mathrm{mOC} 78$

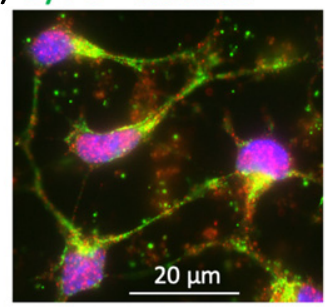

E) $p 62$

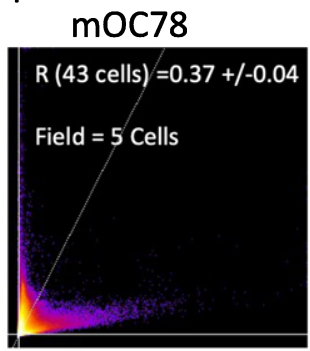

F) p62 mOC78

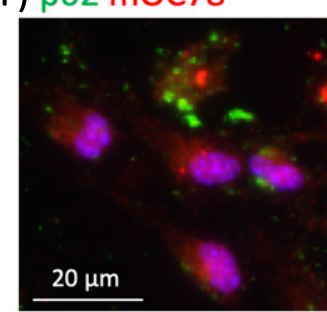

G) Correlations averaged for all iA $\beta$ forms

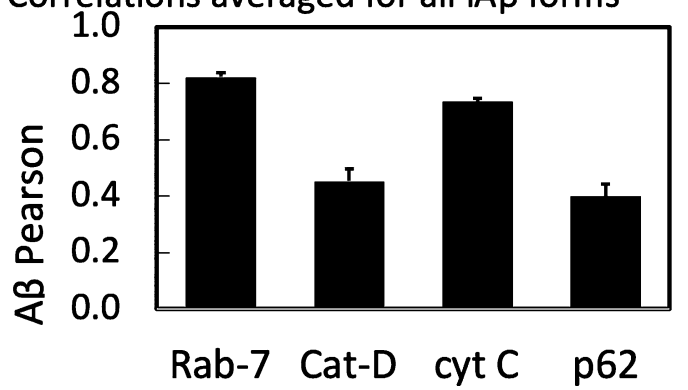

Fig. 7. iA $\beta$ forms colocalize with markers of autophagy, most strongly for mOC78 with late endosome Rab-7. Each flame graph contains the pixels from 7-20 neurons of one field. Each point is the Pearson correlation of intensities in one pixel with brighter colors indicating higher prevalence of specific colocalization intensities. Axes show automated cutoffs for pixels with no overlap. Statistics are for 6 fields. A) Equally high Rab-7 colocalization (y-axis) with i) mOC78, ii) $\mathrm{A} \beta_{45}$, and iii) CTF (each $\mathrm{x}$-axis). Neurons from an 11-month-old male 3xTg-AD mouse, file 180511, composite images shown in Fig 3. B) Slightly lower colocalization of Cat D with i) mOC78 than with Rab-7; much lower cathepsin $\mathrm{D}$ correlations with ii) $\mathrm{A} \beta_{45}$ and iii) $\mathrm{A} \beta \mathrm{PP}-\mathrm{CTF}$. Neurons from a 6-month-old female 3xTg-AD mouse, file 170901. C) Strong colocalization of cytochrome $\mathrm{C}$ with mOC78 as exemplified in D) field 1 from a 5-month-old 3xTg-AD male, file 171005. E) Poor colocalization of p62 with mOC78 as exemplified from F) field 4 from a 12-month-old 3xTg-AD female, file 170804 of data. G) Highest Pearson correlations averaged for three iA $\beta$ forms with Rab-7, followed by cytochrome $\mathrm{C}$ (similar for all forms, 2-month-old non-Tg and 3xTg-AD female file 171017, 5-month-old non-Tg and 3xTg-AD male file 171005, 11-month-old 3xTg-AD male file 180511. Significantly lower correlations for cathepsin D and p62 (cat-D: CTF average $r=0.37, n=2$ 6-month-old 3xTg-AD female file 171213, 11-month-old female file 170830. A $\beta_{45}$ average $r=0.49, n=3$ 6-month-old 3xTg-AD female file 170901, 9-month-old 3xTg-AD male file 170428, 10month-old 3xTg-AD male file 170428. p62: $r=0.4310$-month-old 3xTg-AD male file 170512, $r=0.37$ 11-month-old 3xTg-AD female file 170804).

\section{Differential in vitro kinetics of accumulation of iA $\beta$ markers}

Neurons isolated from adult brains begin as spherical somata. As they regenerate axons and dendrites in culture, the total cellular mass increases. We compared this mass effect to production of $i A \beta$ forms as determined by antibodies against $\mathrm{A} \beta_{45}$, $\mathrm{mOC} 78$, anti-AßPP-CTF, and the lysosomal marker Cat D.
With days in vitro, mass as integrated density per cell and objects per cell increased at least four-fold in both ages in all measures (Fig. 8). The older age levels of $A \beta_{45}$ were about double those of the middle-age neurons at early times (Fig. 8B, F). At later times, AßPP-CTF production increased (Fig. 8C, G). Oldage neuronal mOC78 levels were almost 100 -fold higher in density and 6-fold higher in objects per cell than middle-age neurons (Fig. 8D, H). These large 

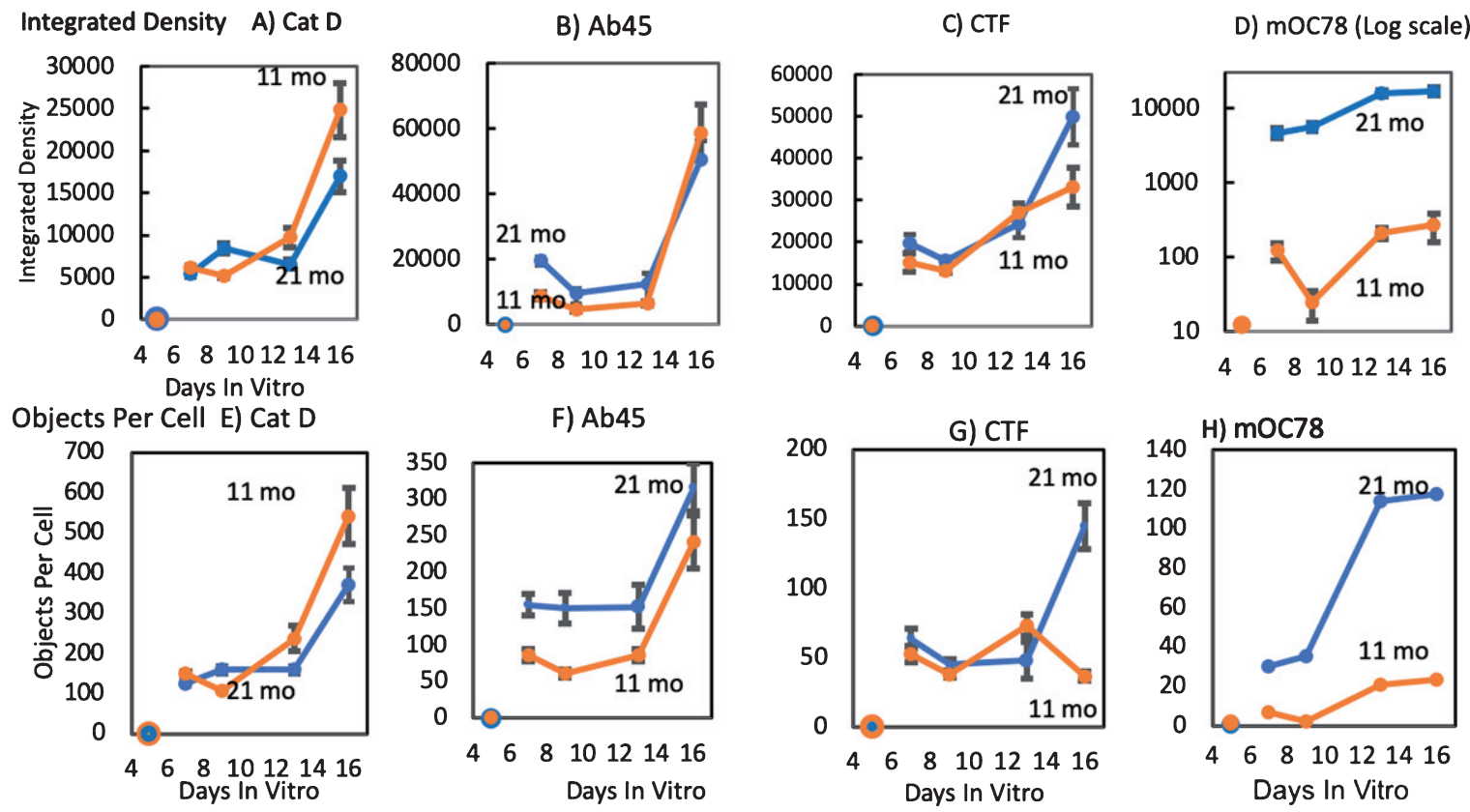

Fig. 8. Greatest age-related increases in mOC78 by in vitro kinetics. Immunoreactive integrated density of (A) lysosomal Cathepsin D and (B-D) iA $\beta$ forms for neurons from an 11 (orange) and a 21-month-old (blue) female 3xTg-AD mouse. These results are paralleled by measures of objects counted per cell $(\mathrm{E}-\mathrm{H})$ from the same cells. Similar kinetics for anti-cathepsin D immunoreactivity $(\mathrm{A}, \mathrm{E})$, and iA $\beta$ forms (A, E), A $\beta_{45}(\mathrm{~B}, \mathrm{~F}), \mathrm{A} \beta \mathrm{PP}-\mathrm{CTF}(\mathrm{C}, \mathrm{G})$, and mOC78 (D, H). Note that panel D, Y axis is log scale. File 170712.

effects suggest that age alters the development and maturation of mOC78 iA $\beta$ aggregate forms in excess of the increase in neuron mass or CTF.

\section{Modulation of autophagy and glutamate affects A $\beta_{45}$ levels}

We pharmacologically modulated autophagy to determine the effects on $A \beta_{45}$ levels. If $A \beta_{45}$ was being cleared by autophagy, then inhibition of autophagy would be expected to cause $A \beta_{45}$ accumulation and promotion of autophagy would accelerate $A \beta_{45}$ clearance. As a negative control, we used bafilomycin to inhibit the proton-pumping ATPase that acidifies lysosomes [47] and prevent fusion of lysosomes with autophagic vesicles [48]. Figure 9A shows the expected decrease in cathepsin D immunoreactive density with bafilomycin, although the size of reactive objects per cell did not decrease (Fig. 9B). Independently, p62 for assembly of autophagosomes also responded with a decrease in density and object size (Fig. 9C, D). As a positive control to stimulate autophagy, we used the inhibitor of mTOR, rapamycin [49]. Rapamycin increased cathepsin D and p62 levels (Fig. 9A, C) as well as cathepsin object size (Fig. 9B) and objects per cell from 112 to 184 (not shown). Interestingly, iA $\beta_{45}$ immunoreactivity increased with either inhibition or promotion of autophagy (Fig. 9E) and imaged particle sizes increased with rapamycin (Fig. 9F). Furthermore, colocalization of $\mathrm{iA} \beta_{45}$ with cathep$\sin \mathrm{D}$ was unchanged by either change in autophagy $(r=0.58 \pm 0.04)$. In contrast, the lower correlation of iA $\beta_{45}$ with p62 $(r=0.43 \pm 0.03)$ was decreased further by promotion of autophagy with rapamycin to $0.32 \pm 0.03$. These results need to be viewed in two contexts, differences in iA $\beta_{45}$ localization to the endosomal versus the macroautophagy branch of autophagy and which pathway is affected in the $3 \times \mathrm{Tg}-\mathrm{AD}$ neurons. Figure $9 \mathrm{~A}$ and $\mathrm{C}$ show that bafilomycin inhibition of lysosomal acidification and degradation activity increased iA $\beta$ and long iA $\beta$. Rapamycin which increases autophagy and increases the uptake of A $\beta P P$ and CTF substrates into endosomes and autophagosomes, resulted in an increase in $\mathrm{iA} \beta$ and long $\mathrm{iA} \beta$ steady state levels by a different mechanism. Thus, Fig. 9E and F treatment with glutamate further shows that $\mathrm{iA} \beta_{45}$ immunoreactivity is increased by the $\mathrm{Ca}$ and energetic load of glutamate as well as bafilomycin alone, but the combination of bafilomycin + glutamate further increased iA $\beta_{45}$. This suggests that an energetic load contributes to 

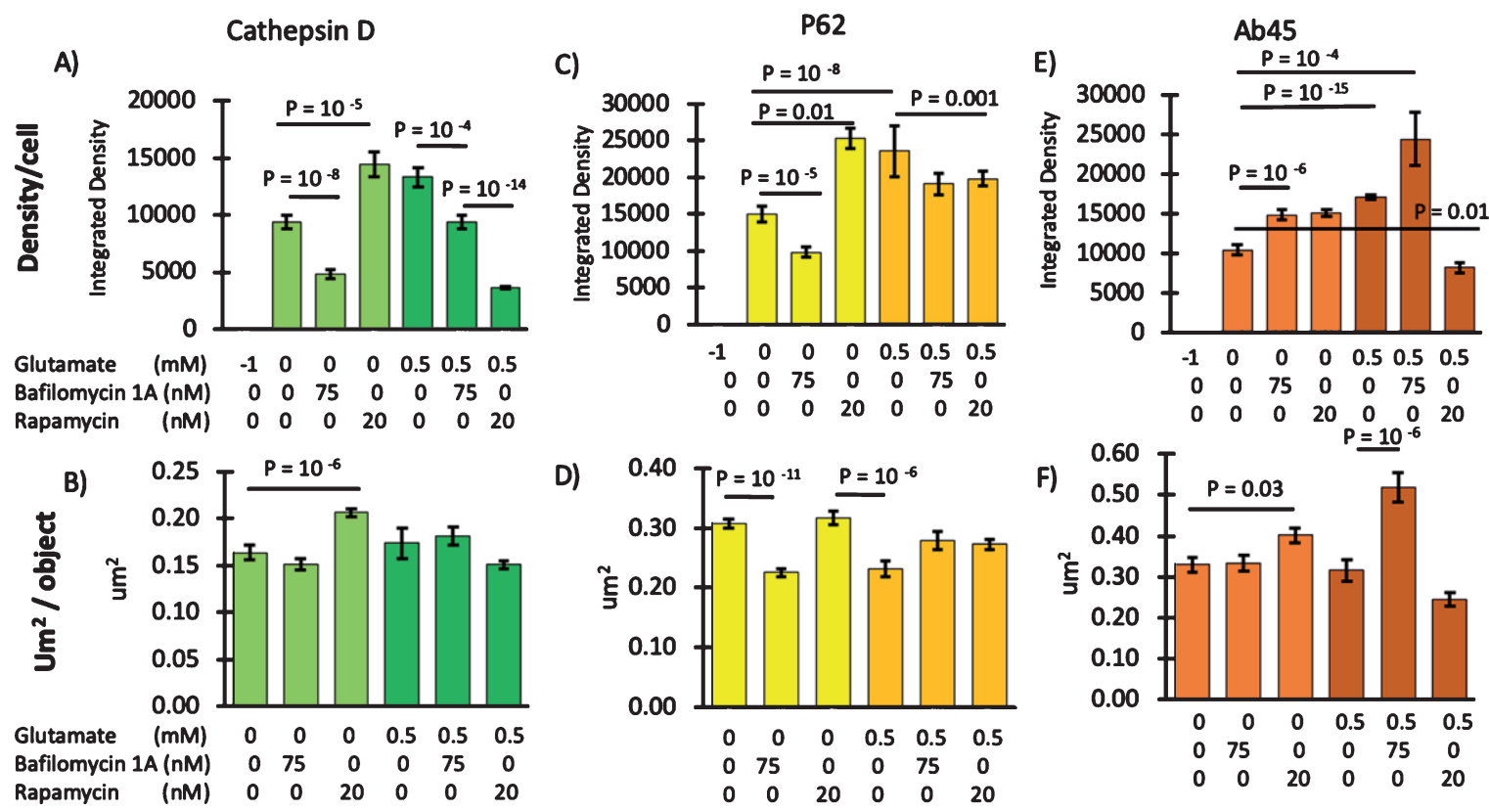

Fig. 9. Autophagy of $\mathrm{iA} \beta_{45}$ compared to a glutamate burden. A) Cathepsin D immunoreactiivty for lysosomes as integrated density per cell and B) as object size. C, D) Same measures in sister cultures for macroautophagic marker p62. E, F) same measures for iA $\beta_{45}$. For each stain paired with $A \beta_{45}$ stain, sister cultures were treated with the indicated concentrations of glutamate, the autophagic inhibitor bafilomycin $1 \mathrm{~A}$ or the autophagic stimulator rapamycin. " -1 " represents the adjustment of detection threshold to zero for a sister culture in which the primary antibody was omitted. Each bar is the average from 31-45 neurons from a 3xTg 10-month-old male, file 170512.

iA $\beta_{45}$ production. The reduction in $\mathrm{A} \beta$ levels following stimulation by rapamycin + glutamate suggests both that autophagic clearance was impaired at rest and more so following a glutamate pulse, but that inhibition of an intact autophagic machinery needed rapamycin to reverse it. We interpret these results as increased iA $\beta_{45}$ accumulation from backup of inhibited autophagy and increased $i A \beta_{45}$ buildup from promotion of autophagy with inability to degrade or secrete $i A \beta_{45}$.

\section{DISCUSSION}

\section{New antibodies dissect autophagic steps for accumulation of $i A \beta$}

The composition and aggregation state of iA $\beta$ has been one of the major controversies surrounding the significance of $i A \beta$. Because of limitations on the specificity of anti-A $\beta$ antibodies, many investigators have argued that intraneuronal amyloid was actually "normal" A $\beta P P$ or A $\beta P P-C T F 99$. In cultured adult neurons from $3 \times \mathrm{Tg}$-AD mice across the age-span with novel antibodies against $A \beta_{45}$ and aggregated forms (mOC78 [17]), we address impor- tant mechanistic questions about the pathways of iA $\beta$ production and removal with implications for possible pathology and therapeutics. Here, we found evidence for substantial accumulation of intracellu$\operatorname{lar} \mathrm{A} \beta$-related forms, including A $\beta$ PP-CTF, long A $\beta$ peptides ending at residue $45 \mathrm{C}$-terminal peptide and aggregated $\mathrm{A} \beta$ in the form of mOC78 immunoreactive material. Interestingly, all three forms were present in Rab-7 late endosomes, while accumulation into cathepsin $D$ positive lysosomes was strongest for the mOC78 aggregated iA $\beta$ (Fig. 1), which may be indicative of further autophagic processing of the late endosomes.

\section{Autophagy}

AD-related deficits in lysosomal and autophagic processing are well established $[45,46]$, but the contributions of aging to different forms of iA $\beta$ are not well documented. Here we were able to compare the colocalization of three forms of iA $\beta$ to four steps in autophagy in two pathways, endocytosis and macroautophagy. A $\beta P P$ interacts with BACE ( $\beta$-secretase) at the plasma membrane [50], is internalized and concentrated with BACE in endo- 
somes [51-53]. Whether BACE cleavage of A $\beta P P$ to AßPP-CTF99 occurs first at the plasma membrane or only subsequent to endocytosis is unclear, especially since most studies of A $\mathrm{PPP}$ processing are done in non-neuronal cells and have not studied how an aging environment and signaling affect this process [53, 54] (Fig. 1). Early endosomal trafficking is controlled by Rab5. Maturation proceeds by replacement of Rab5 with Rab7 in late endosomes. The next step is either return to the plasma membrane for receptor recycling and exocytosis [51] or fusion with lysosomes, termed autophagolysosomes. Here we see higher levels of $A \beta_{45}$ and aggregated $A \beta$ in late endosomes than in cathepsin $D$ positive autophagolysosomes, suggesting that some CTF99 is processed by gamma-secretase to $A \beta$ in late endosomes. Localized activation of BACE in endosomes and binding of BACE1 to Rab5 and AßPP is thought to generate CTF99 and vesicle enlargement [45]. Separately, mitochondrial macroautophagy enters from a separate pathway for fusion with lysosomes. Both a late endosomal compartment and mitochondria showed strong colocalization with iA $\beta$ forms. A weaker colocalization signal with p62-directed formation of macro autophagosomes together with the above-mentioned weaker lysosomal colocalization may indicate age and AD-related deficits in several steps of autophagy. Autophagy may be blocked by the neuron's inability to degrade or secrete aggregates of $A \beta_{45}$. Age-related deficits in bioenergetic capacity [55] may be an upstream cause of endosomal or lysosomal limitations on ATPase acidification of these organelles [56]. Our results here by bafilomycin inhibition of acidification showed decreased cathepsin D positive lysosomes, and macroautophagic p62 levels, while $A \beta_{45}$ levels increased. These results suggest additional capacity in these neurons to produce more $A \beta_{45}$. A further increase by glutamate in the presence of bafilomycin indicates additional signaling mechanisms for increased $A \beta_{45}$. Conversely, rapamycin treatment to stimulate the mTOR pathway of autophagy promoted cathepsin $\mathrm{D}$ and $\mathrm{p} 62$ levels, while only modestly increased $A \beta_{45}$ levels were seen with glutamate stimulated inhibition of autophagy. Recently, Fang et al. 57] demonstrated that stimulation of mitophagy through $\mathrm{NAD}^{+}$supplementation, urolithin $\mathrm{A}$, and actinonin diminished iA $\beta$ in human neuroblastoma cells and improved cognition in A $\beta P P / P S 1$ mice. These results support ageand AD-related deficits in the mTOR pathway [50] and deficits in pAkt modulation of this pathway [58]. Further work is needed to discriminate between the fusion process, aspects of energized motor proteins for vesicle trafficking [59], processing of the $A \beta$ CTF motif $[11,60]$, processing of cytoplasmic $A \beta$ by chaperone mediated autophagy [61] in age-related effects on iA $\beta$ accumulation. These results confirm and extend histology and immunoblot results of agerelated changes in late-endosome regulation in the AßPP/PS1 mouse brain [39].

\section{Aging}

Age contributed the largest effects seen here on $\mathrm{iA} \beta$, both as $\mathrm{A} \beta_{45}$ and aggregated mOC78 immunoreactivity. $A \beta_{45}$ and mOC78 were seen to increase logarithmically with age. The increases were greater than 10-fold across the age-span of the transgenic mouse, both in terms of immunoreactive material per neuron and objects per neuron. The distribution of object sizes was well-fit by a log$\log$ relationship, with similar slopes for non- $\mathrm{Tg}$ and 3xTg-AD neurons, suggesting a similar mechanism of formation without the transgenes. An excess of large particles in the $3 \times \mathrm{Tg}$-AD neurons from middle to old age, particles approaching a large portion of a whole cell, suggest a process unable to be controlled. Our kinetic studies of development in culture with constant nutrients, first of dendrites, then axons and synapses, indicate the strongest effects on mOC78 aggregation of iA $\beta$. These log-log distributions are reminiscent of particle nucleation followed by increasing creation of surface area for additional aggregation, a snow-ball effect. Intracellular aggregation of externally added $A \beta_{1-42}$ was seen to aggregate up to $0.2 \mu \mathrm{m}$ diameter in SH-SY5Y neuroblastoma cells [62], but the extent could have been influenced by the size of the label, the undifferentiated state of the cells and lack of an aging epigenome. The differences with age suggest that either the rate of formation of iA $\beta$ increases or their rate of autophagic clearance decreases with age. Glutamate could do either. Dissection of the mechanism could be informed by age-related effects of inhibition or promotion of autophagy. Age-related energetic deficits in neurons may be partially responsible [55, 63-66], since agerelated deficits in NADH levels can be restored in neurons with precursors to NAD [45, 67].

\section{Tau and glutamate}

We also found phosphorylated tau as Alz-50 immunoreactivity deposited in forms resembling neurofibrillary tangles in neurons with iA $\beta$, espe- 
cially in neurons from old animals. Alz-50 is an early marker seen in neurofibrillary tangles in AD brains as well as in normal-appearing neurons [31, 32]. It remains to be determined how similar our structures are to the paired helical filaments induced by glutamate in cultured human fetal spinal cord neurons [68] or embryonic rat neurons [69]. A mechanism for the calcium effects on $\mathrm{iA} \beta_{45}$ and aggregated tau could be due to the well-known effects of glutamate on $\mathrm{Ca}^{++}$ entry to stimulate calcineurin [70], old-age limits on calcineurin activity through phosphorylation [71], effects on $\mathrm{A} \beta \mathrm{PP}$ processing of AD-related inhibition of calcineurin by DSCR1 [72], or the bioenergetic load on the Na-K-ATPase and Ca-ATPase pumps. Alternatively, the oxidative stress of glutamate exposure could induce energy deficits or impair other essential functions that contribute to $\mathrm{iA} \beta$, as it does in neuroblastoma cells [73].

\section{Processing and conclusion}

We speculate that age-related signaling for inhibition of C-terminal trimming by gamma-secretase increases $A \beta_{45}$ levels whose hydrophobic properties promote aggregation [Brewer et al., in preparation]. Previous studies have reported that long $A \beta$ peptides $A \beta_{1-47}$ and $A \beta_{1-52}$ aggregate much faster than even $A \beta_{42}$ [74] and that these long $A \beta s$ are retained and not secreted from cells [75, 76]. Early work proposed dynamic controls of the processing of $A \beta$ to regulate the routing toward intra- versus extracellular accumulation of $A \beta$ [77]. The interpretations of these results have metabolic and possibly mechanistic implications for impaired cognition. Some gammasecretase inhibitors may promote the increase of toxic iA $\beta$ due to inhibition of the processivity [78]. Even shorter amyloid fragments of $A \beta_{40}$ and $A \beta_{42}$ may be more easily exported from the neurons and vasculature. Understanding the mechanism of age-related changes in iA $\beta$ processing may finally lead to application of countermeasures to prolong dementia-free health span $[19,79]$.

\section{ACKNOWLEDGMENTS}

This work was supported by funds from the UC Irvine Foundation to GB, R56 AG056507-01 to CG, and RF1 AG058218 to GB and CG.

Authors' disclosures available online (https:// www.j-alz.com/manuscript-disclosures/19-0835r1).

\section{SUPPLEMENTARY MATERIAL}

The supplementary material is available in the electronic version of this article: http://dx.doi.org/ 10.3233/JAD-190835.

\section{REFERENCES}

[1] Selkoe DJ (1991) The molecular pathology of Alzheimer's disease. Neuron 6, 487-498.

[2] Hardy J, Allsop D (1991) Amyloid deposition as the central event in the aetiology of Alzheimer's disease. Trends Pharmacol Sci 12, 383-388.

[3] Cline EN, Bicca MA, Viola KL, Klein WL (2018) The amyloid-beta oligomer hypothesis: Beginning of the third decade. J Alzheimers Dis 64, S567-S610.

[4] Doody RS, Raman R, Farlow M, Iwatsubo T, Vellas B, Joffe S, Kieburtz K, He F, Sun X, Thomas RG, Aisen PS, Alzheimer's Disease Cooperative Study Steering Committee, Siemers E, Sethuraman G, Mohs R, Semagacestat Study Group (2013) A phase 3 trial of semagacestat for treatment of Alzheimer's disease. $N$ Engl J Med 369, 341-350.

[5] Quintero-Monzon O, Martin MM, Fernandez MA, Cappello CA, Krzysiak AJ, Osenkowski P, Wolfe MS (2011) Dissociation between the processivity and total activity of gamma-secretase: Implications for the mechanism of Alzheimer's disease-causing presenilin mutations. Biochemistry 50, 9023-9035.

[6] Cacquevel M, Aeschbach L, Houacine J, Fraering PC (2012) Alzheimer's disease-linked mutations in presenilin-1 result in a drastic loss of activity in purified gamma-secretase complexes. PLoS One 7, e35133.

[7] Fernandez MA, Klutkowski JA, Freret T, Wolfe MS (2014) Alzheimer presenilin-1 mutations dramatically reduce trimming of long amyloid beta-peptides (Abeta) by gammasecretase to increase 42-to-40-residue Abeta. J Biol Chem 289, 31043-31052.

[8] Coric V, van Dyck CH, Salloway S, Andreasen N, Brody M, Richter RW, Soininen H, Thein S, Shiovitz T, Pilcher G, Colby S, Rollin L, Dockens R, Pachai C, Portelius E, Andreasson U, Blennow K, Soares H, Albright C, Feldman HH, Berman RM (2012) Safety and tolerability of the gamma-secretase inhibitor avagacestat in a phase 2 study of mild to moderate Alzheimer disease. Arch Neurol 69, 1430-1440.

[9] Billings LM, Oddo S, Green KN, McGaugh JL, LaFerla FM (2005) Intraneuronal abeta causes the onset of early Alzheimer's disease-related cognitive deficits in transgenic mice. Neuron 45, 675-688.

[10] Gimenez-Llort L, Blazquez G, Canete T, Johansson B, Oddo S, Tobena A, LaFerla FM, Fernandez-Teruel A (2007) Modeling behavioral and neuronal symptoms of Alzheimer's disease in mice: A role for intraneuronal amyloid. Neurosci Biobehav Rev 31, 125-147.

[11] Muresan V, Varvel NH, Lamb BT, Muresan Z (2009) The cleavage products of amyloid-beta precursor protein are sorted to distinct carrier vesicles that are independently transported within neurites. J Neurosci 29, 35653578.

[12] Leon WC, Canneva F, Partridge V, Allard S, Ferretti MT, DeWilde A, Vercauteren F, Atifeh R, Ducatenzeiler A, Klein W, Szyf M, Alhonen L, Cuello AC (2010) A novel transgenic rat model with a full Alzheimer's-like amyloid pathology 
displays pre-plaque intracellular amyloid-beta-associated cognitive impairment. J Alzheimers Dis 20, 113-126.

[13] Currais A, Fischer W, Maher P, Schubert D (2017) Intraneuronal protein aggregation as a trigger for inflammation and neurodegeneration in the aging brain. FASEB J 31, 5-10.

[14] Takahashi RH, Nagao T, Gouras GK (2017) Plaque formation and the intraneuronal accumulation of beta-amyloid in Alzheimer's disease. Pathol Int 67, 185-193.

[15] Ferretti MT, Bruno MA, Ducatenzeiler A, Klein WL, Cuello AC (2012) Intracellular Abeta-oligomers and early inflammation in a model of Alzheimer's disease. Neurobiol Aging 33, 1329-1342.

[16] Bayer TA, Wirths O (2011) Intraneuronal Abeta as a trigger for neuron loss: Can this be translated into human pathology? Biochem Soc Trans 39, 857-861

[17] Pensalfini A, Albay R 3rd, Rasool S, Wu JW, Hatami A, Arai H, Margol L, Milton S, Poon WW, Corrada MM, Kawas CH, Glabe CG (2014) Intracellular amyloid and the neuronal origin of Alzheimer neuritic plaques. Neurobiol Dis 71, 5361.

[18] Sosna J, Philipp S, Albay R 3rd, Reyes-Ruiz JM, BagliettoVargas D, LaFerla FM, Glabe CG (2018) Early long-term administration of the CSF1R inhibitor PLX3397 ablates microglia and reduces accumulation of intraneuronal amyloid, neuritic plaque deposition and pre-fibrillar oligomers in 5XFAD mouse model of Alzheimer's disease. $\mathrm{Mol} \mathrm{Neu-}$ rodegener $13,11$.

[19] Brewer GJ (2010) Epigenetic oxidative redox shift (EORS) theory of aging unifies the free radical and insulin signaling theories. Exp Gerontol 45, 173-179.

[20] Kumar A, Yegla B, Foster TC (2018) Redox signaling in neurotransmission and cognition during aging. Antioxid Redox Signal 28, 1724-1745.

[21] Oddo S, Caccamo A, Shepherd JD, Murphy MP, Golde TE, Kayed R, Metherate R, Mattson MP, Akbari Y, LaFerla FM (2003) Triple-transgenic model of Alzheimer's disease with plaques and tangles. Intracellular abeta and synaptic dysfunction. Neuron 39, 409-421.

[22] Oakley H, Cole SL, Logan S, Maus E, Shao P, Craft J, Guillozet-Bongaarts A, Ohno M, Disterhoft J, Van Eldik L, Berry R, Vassar R (2006) Intraneuronal beta-amyloid aggregates, neurodegeneration, and neuron loss in transgenic mice with five familial Alzheimer's disease mutations: Potential factors in amyloidplaque formation. JNeurosci $\mathbf{2 6}$, 10129-10140.

[23] Brewer GJ, Torricelli JR (2007) Isolation and culture of adult neurons and neurospheres. Nat Protoc 2, 1490-1498.

[24] Brewer GJ, Torricelli JR, Evege EK, Price PJ (1993) Optimized survival of hippocampal neurons in B27supplemented Neurobasal, a new serum-free medium combination. J Neurosci Res 35, 567-576.

[25] Cataldo AM, Hamilton DJ, Barnett JL, Paskevich PA, Nixon RA (1996) Properties of the endosomal-lysosomal system in the human central nervous system: Disturbances mark most neurons in populations at risk to degenerate in Alzheimer's disease. J Neurosci 16, 186-199.

[26] Vardarajan BN, Bruesegem SY, Harbour ME, Inzelberg R, Friedland R, St George-Hyslop P, Seaman MN, Farrer LA (2012) Identification of Alzheimer disease-associated variants in genes that regulate retromer function. Neurobiol Aging 33, 2231 e2215-2231 e2230.

[27] Hyttinen JM, Niittykoski M, Salminen A, Kaarniranta K (2013) Maturation of autophagosomes and endosomes: A key role for Rab7. Biochim Biophys Acta 1833,503-510.
[28] Arnoult D, Grodet A, Lee YJ, Estaquier J, Blackstone C (2005) Release of OPA1 during apoptosis participates in the rapid and complete release of cytochrome c and subsequent mitochondrial fragmentation. $J$ Biol Chem 280, 35742-35750.

[29] Joshi G, Gan KA, Johnson DA, Johnson JA (2015) Increased Alzheimer's disease-like pathology in the APP/ PS1DeltaE9 mouse model lacking Nrf2 through modulation of autophagy. Neurobiol Aging 36, 664-679.

[30] Hatami A, Albay R 3rd, Monjazeb S, Milton S, Glabe CG (2014) Monoclonal antibodies against Abeta42 fibrils distinguish multiple aggregation state polymorphisms in vitro and in Alzheimer disease brain. J Biol Chem 289, 3213132143.

[31] Wolozin B, Davies P (1987) Alzheimer-related neuronal protein A68: Specificity and distribution. Ann Neurol 22, 521-526.

[32] Hyman BT, Van Hoesen GW, Wolozin BL, Davies P, Kromer LJ, Damasio AR (1988) Alz-50 antibody recognizes Alzheimer-related neuronal changes. Ann Neurol 23, 371-379.

[33] Brewer GJ (1997) Isolation and culture of adult rat hippocampal neurons. J Neurosci Meth 71, 143-155.

[34] Patel JR, Brewer GJ (2003) Age-related changes in neuronal glucose uptake in response to glutamate and beta-amyloid. J Neurosci Res 72, 527-536.

[35] Jones TT, Brewer GJ (2010) Age-related deficiencies in complex I endogenous substrate availability and reserve capacity of complex IV in cortical neuron electron transport. Biochim Biophys Acta 1797, 167-176.

[36] Costes SV, Daelemans D, Cho EH, Dobbin Z, Pavlakis G, Lockett S (2004) Automatic and quantitative measurement of protein-protein colocalization in live cells. Biophys $J \mathbf{8 6}$, 3993-4003.

[37] Adler J, Parmryd I (2010) Quantifying colocalization by correlation: The Pearson correlation coefficient is superior to the Mander's overlap coefficient. Cytometry A 77, 733742.

[38] Wong YC, Ysselstein D, Krainc D (2018) Mitochondrialysosome contacts regulate mitochondrial fission via RAB7 GTP hydrolysis. Nature 554, 382-386.

[39] Ba L, Chen XH, Chen YL, Nie Q, Li ZJ, Ding FF, Zhang M (2017) Distinct Rab7-related endosomalautophagic-lysosomal dysregulation observed in cortex and hippocampus in APPswe/PSEN1dE9 mouse model of Alzheimer's disease. Chin Med J (Engl) 130, 2941-2950.

[40] Rogawski MA, Wenk GL (2003) The neuropharmacological basis for the use of memantine in the treatment of Alzheimer's disease. CNS Drug Rev 9, 275-308.

[41] Disterhoft JF, Moyer JR, Thompson LT (1994) The calcium rationale in aging and Alzheimer's disease. Ann NY Acad Sci 747, 382-406.

[42] Ikonomovic MD, Sheffield R, Armstrong DM (1995) AMPA-selective glutamate receptor subtype immunoreactivity in the hippocampal formation of patients with Alzheimer's disease. Hippocampus 5, 469-486.

[43] Masliah E, Alford M, Deteresa R, Mallory M, Hansen L (1996) Deficient glutamate transport is associated with neurodegeneration in Alzheimer's disease. Ann Neurol 40, 759-766.

[44] Um JW, Kaufman AC, Kostylev M, Heiss JK, Stagi M, Takahashi H, Kerrisk ME, Vortmeyer A, Wisniewski T, Koleske AJ, Gunther EC, Nygaard HB, Strittmatter SM (2013) Metabotropic glutamate receptor 5 is a coreceptor for 
Alzheimer abeta oligomer bound to cellular prion protein. Neuron 79, 887-902.

[45] Colacurcio DJ, Pensalfini A, Jiang Y, Nixon RA (2018) Dysfunction of autophagy and endosomal-lysosomal pathways: Roles in pathogenesis of Down syndrome and Alzheimer's disease. Free Radic Biol Med 114, 40-51.

[46] Reddy PH, Yin X, Manczak M, Kumar S, Jangampalli Adi P, Vijayan M, Reddy AP (2018) Mutant APP and Amyloid beta-induced defective autophagy, mitophagy, mitochondrial structural and functional changes and synaptic damage in hippocampal neurons from Alzheimer's disease. Hum Mol Genet 27, 2502-2516.

[47] Mousavi SA, Kjeken R, Berg TO, Seglen PO, Berg T, Brech A (2001) Effects of inhibitors of the vacuolar proton pump on hepatic heterophagy and autophagy. Biochim Biophys Acta 1510, 243-257.

[48] Yamamoto A, Tagawa Y, Yoshimori T, Moriyama Y, Masaki R, Tashiro Y (1998) Bafilomycin A1 prevents maturation of autophagic vacuoles by inhibiting fusion between autophagosomes and lysosomes in rat hepatoma cell line, H-4-II-E cells. Cell Struct Funct 23, 33-42.

[49] Talboom JS, Velazquez R, Oddo S (2015) The mammalian target of rapamycin at the crossroad between cognitive aging and Alzheimer's disease. Aging Mech Disease 1, 15008.

[50] Kinoshita A, Fukumoto H, Shah T, Whelan CM, Irizarry MC, Hyman BT (2003) Demonstration by FRET of BACE interaction with the amyloid precursor protein at the cell surface and in early endosomes. J Cell Sci 116, 3339-3346.

[51] Cirrito JR, Kang JE, Lee J, Stewart FR, Verges DK, Silverio LM, Bu G, Mennerick S, Holtzman DM (2008) Endocytosis is required for synaptic activity-dependent release of amyloid-beta in vivo. Neuron $\mathbf{5 8}, 42-51$.

[52] Das U, Wang L, Ganguly A, Saikia JM, Wagner SL, Koo EH, Roy S (2016) Visualizing APP and BACE-1 approximation in neurons yields insight into the amyloidogenic pathway. Nat Neurosci 19, 55-64.

[53] Sun J, Roy S (2018) The physical approximation of APP and BACE-1: A key event in Alzheimer's disease pathogenesis. Dev Neurobiol 78, 340-347.

[54] Cole SL, Vassar R (2007) The Alzheimer's disease betasecretase enzyme, BACE1. Mol Neurodegener 2, 22.

[55] Ghosh D, LeVault KR, Barnett AJ, Brewer GJ (2012) A reversible early oxidized redox state that precedes macromolecular ROS damage in aging nontransgenic and 3xTg-AD mouse neurons. J Neurosci 32, 5821-5832.

[56] Eitan E, Suire C, Zhang S, Mattson MP (2016) Impact of lysosome status on extracellular vesicle content and release. Ageing Res Rev 32, 65-74.

[57] Fang EF, Hou Y, Palikaras K, Adriaanse BA, Kerr JS, Yang B, Lautrup S, Hasan-Olive MM, Caponio D, Dan X, Rocktaschel P, Croteau DL, Akbari M, Greig NH, Fladby T, Nilsen H, Cader MZ, Mattson MP, Tavernarakis N, Bohr VA (2019) Mitophagy inhibits amyloid-beta and tau pathology and reverses cognitive deficits in models of Alzheimer's disease. Nat Neurosci 22, 401-412.

[58] Ghosh D, Brewer GJ (2014) External cys/cySS redox state modification controls the intracellular redox state and neurodegeneration via Akt in aging and Alzheimer's disease mouse model neurons. J Alzheimers Dis 42, 313-324.

[59] Bejarano E, Murray JW, Wang X, Pampliega O, Yin D, Patel B, Yuste A, Wolkoff AW, Cuervo AM (2018) Defective recruitment of motor proteins to autophagic compartments contributes to autophagic failure in aging. Aging Cell 17, e12777.
[60] Park JS, Kim DH, Yoon SY (2016) Regulation of amyloid precursor protein processing by its KFERQ motif. $B M B$ Rep 49, 337-342.

[61] Kaushik S, Cuervo AM (2018) The coming of age of chaperone-mediated autophagy. Nat Rev Mol Cell Biol 19, 365-381.

[62] Esbjorner EK, Chan F, Rees E, Erdelyi M, Luheshi LM, Bertoncini CW, Kaminski CF, Dobson CM, Kaminski Schierle GS (2014) Direct observations of amyloid beta selfassembly in live cells provide insights into differences in the kinetics of Abeta(1-40) and Abeta(1-42) aggregation. Chem Biol 21, 732-742.

[63] Ghosh D, Levault KR, Brewer GJ (2014) Relative importance of redox buffers GSH and $\mathrm{NAD}(\mathrm{P}) \mathrm{H}$ in age-related neurodegeneration and Alzheimer disease-like mouse neurons. Aging Cell 13, 631-640.

[64] Ghosh D, Levault KR, Brewer GJ (2014) Dual-energy precursor and nuclear erythroid-related factor 2 activator treatment additively improve redox glutathione levels and neuron survival in aging and Alzheimer mouse neurons upstream of reactive oxygen species. Neurobiol Aging 35, 179-190.

[65] Dong Y, Sameni S, Digman MA, Brewer GJ (2019) Reversibility of age-related oxidized free NADH redox states in Alzheimer's disease neurons by imposed external Cys/CySS redox shifts. Sci Rep 9, 11274.

[66] Dong Y, Digman,MA, Brewer GJ (2019) Age- and ADrelated redox state of NADH in subcellular compartments by fluorescence lifetime imaging microscopy. Geroscience 41, 51-67.

[67] Liu D, Gharavi R, Pitta M, Gleichmann M, Mattson MP (2009) Nicotinamide prevents NAD+ depletion and protects neurons against excitotoxicity and cerebral ischemia: NAD+ consumption by SIRT1 may endanger energetically compromised neurons. Neuromolecular Med 11, 28-42.

[68] De Boni U, McLachlan DR (1985) Controlled induction of paired helical filaments of the Alzheimer type in cultured human neurons, by glutamate and aspartate. J Neurol Sci 68, 105-118.

[69] Brewer GJ, Ashford JW (1992) Human serum stimulates Alzheimer markers in cultured hippocampal neurons. J Neurosci Res 33, 355-369.

[70] Hopp SC, Bihlmeyer NA, Corradi JP, Vanderburg C, Cacace AM, Das S, Clark TW, Betensky RA, Hyman BT, Hudry E (2018) Neuronal calcineurin transcriptional targets parallel changes observed in Alzheimer disease brain. J Neurochem 147, 24-39.

[71] Foster TC, Sharrow KM, Masse JR, Norris CM, Kumar A (2001) Calcineurin links Ca2+ dysregulation with brain aging. J Neurosci 21, 4066-4073.

[72] Shaw JL, Zhang S, Chang KT (2015) Bidirectional regulation of amyloid precursor protein-induced memory defects by Nebula/DSCR1: A protein upregulated in Alzheimer's disease and Down syndrome. J Neurosci 35, 11374-11383.

[73] Misonou H, Morishima-Kawashima M, Ihara Y (2000) Oxidative stress induces intracellular accumulation of amyloid beta-protein (Abeta) in human neuroblastoma cells. Biochemistry 39, 6951-6959.

[74] Burdick D, Soreghan B, Kwon M, Kosmoski J, Knauer M, Henschen A, Yates J, Cotman C, Glabe C (1992) Assembly and aggregation properties of synthetic Alzheimer's A4/beta amyloid peptide analogs. J Biol Chem 267, 546-554.

[75] Takami M, Nagashima Y, Sano Y, Ishihara S, MorishimaKawashima M, Funamoto S, Ihara Y (2009) gamma- 
Secretase: Successive tripeptide and tetrapeptide release from the transmembrane domain of beta-carboxyl terminal fragment. $J$ Neurosci 29, 13042-13052.

[76] Olsson TT, Klementieva O, Gouras GK (2018) Prion-like seeding and nucleation of intracellular amyloid-beta. $\mathrm{Neu}$ robiol Dis 113, 1-10.

[77] Oddo S, Caccamo A, Smith IF, Green KN, LaFerla FM (2006) A dynamic relationship between intracellular and extracellular pools of Abeta. Am J Pathol 168, 184-194.
[78] Tagami S, Yanagida K, Kodama TS, Takami M, Mizuta N, Oyama H, Nishitomi K, Chiu YW, Okamoto T, Ikeuchi T, Sakaguchi G, Kudo T, Matsuura Y, Fukumori A, Takeda M, Ihara Y, Okochi M (2017) Semagacestat is a pseudoinhibitor of gamma-secretase. Cell Rep 21, 259-273.

[79] Miller RA (2009) "Dividends" from research on aging-can biogerontologists, at long last, find something useful to do? J Gerontol A Biol Sci Med Sci 64, 157-160. 